NBER WORKING PAPER SERIES

MONETARY AND FISCAL POLICY SWITCHING

Troy Davig

Eric M. Leeper

Hess Chung

Working Paper 10362

http://www.nber.org/papers/w10362

\author{
NATIONAL BUREAU OF ECONOMIC RESEARCH \\ 1050 Massachusetts Avenue \\ Cambridge, MA 02138 \\ March 2004
}

We thank Michael Binder, Chuck Carlstrom, Betty Daniel, Behzad Diba, Jon Faust, Dale Henderson, Jim Nason, Lars Svensson, Martin Uribe and seminar participants at Banco de Portugal, Duke University, the Federal Reserve Bank of Cleveland, the Federal Reserve Board, and the ECB for helpful comments. The views expressed herein are those of the authors and not necessarily those of the National Bureau of Economic Research.

C2004 by Troy Davig, Eric M. Leeper, and Hess Chung. All rights reserved. Short sections of text, not to exceed two paragraphs, may be quoted without explicit permission provided that full credit, including (C) notice, is given to the source. 
Monetary and Fiscal Policy Switching

Troy Davig, Eric M. Leeper, and Hess Chung

NBER Working Paper No. 10362

March 2004

JEL No. E4, E5, E6

\section{$\underline{\text { ABSTRACT }}$}

A growing body of evidence finds that policy reaction functions vary substantially over different periods in the United States. This paper explores how moving to an environment in which monetary and fiscal regimes evolve according to a Markov process can change the impacts of policy shocks. In one regime monetary policy follows the Taylor principle and taxes rise strongly with debt; in another regime the Taylor principle fails to hold and taxes are exogenous. An example shows that a unique bounded non-Ricardian equilibrium exists in this environment.

A computational model illustrates that because agents' decision rules embed the probability that policies will change in the future, monetary and tax shocks always produce wealth effects. When it is possible that fiscal policy will be unresponsive to debt at times, active monetary policy (like a Taylor rule) in one regime is not sufficient to insulate the economy against tax shocks in that regime and it can have the unintended consequence of amplifying and propagating the aggregate demand effects of tax shocks. The paper also considers the implications of policy switching for two empirical issues.

Troy Davig

College of William and Mary

Department of Economics

Morton Hall 110

PO Box 8795

Williamsburg, VA 23187-8795

tadav3@wm.edu
Eric M Leeper

Department of Economics

304 Wylie Hall

Indiana University

Bloomington, IN 47405

and NBER

eleeper@indiana.edu
Hess Chung

Department of Economics

304 Wylie Hall

Indiana University

Bloomington, IN 47405

htchung@indiana.edu 


\title{
MONETARY AND FISCAL POLICY SWITCHING
}

\author{
TROY DAVIG, ERIC M. LEEPER, AND HESS CHUNG
}

\section{INTRODUCTION}

Two themes run through policy analysis: rules determining policy choice are functions of economic conditions; those rules may change over time. The themes reflect the views that actual policy behavior is purposeful, rather than arbitrary, and that good policy adapts to changes in the structure of the economy or to improvements in understanding how policy affects the economy.

A growing body of evidence finds that policy reaction functions vary substantially over different periods in the United States. ${ }^{1}$ In light of this evidence of regime shifts, it is surprising that there is little formal modeling of environments where on-going regime change is stochastic and the objects subject to change are parameters determining how the economy feeds back to policy choice.

This paper is the first step of a broader research agenda that explores how moving to environments in which monetary and fiscal regimes evolve according to a Markov process can change the impacts of and, more generally, the analysis of monetary and fiscal policies. We consider interest rate rules for monetary policy and tax rules for fiscal policy; the rules switch stochastically between two regimes. In one regime monetary policy follows the Taylor (1993) principle and taxes rise strongly with increases in the real value of government debt; in another regime the Taylor principle fails to hold and taxes follow an exogenous stochastic process. Using convenient specifications of policy rules, an analytical example shows that a unique bounded non-Ricardian equilibrium exists in this environment.

Date: This version: February 29, 2004. Previous version: November 4, 2003. We thank Michael Binder, Chuck Carlstrom, Betty Daniel, Behzad Diba, Jon Faust, Dale Henderson, Jim Nason, Lars Svensson, Martin Uribe and seminar participants at Banco de Portugal, Duke University, the Federal Reserve Bank of Cleveland, the Federal Reserve Board, and the ECB for helpful comments. Affiliations: Davig, The College of William and Mary (tadav3@wm.edu); Leeper, Indiana University and NBER (eleeper@indiana.edu); Chung, Indiana University (htchung@indiana.edu).

${ }^{1}$ For example, see Taylor (1999a) or Clarida, Gali, and Gertler (2000) for estimates of monetary policy rules and Taylor (2000) or Auerbach (2002) for estimates of tax policy rules. Favero and Monacelli (2003) explicitly model regime switching in their estimates of monetary and tax policy rules. 
More standard forms of policy rules require that the model be solved numerically. We use a computational model to derive the impacts of exogenous changes in monetary and tax policies in a regime-switching environment and contrast those impacts with their fixed-regime counterparts. When regimes switch, agents' decision rules embed the probability that policies will change in the future and, in consequence, monetary and tax shocks always produce wealth effects. Conventional fixed-regime analyses have found that active monetary policy (like a Taylor rule), which is designed to stabilize aggregate demand and inflation, requires that fiscal policy adjust taxes in response to debt. In contrast, when regimes change and it is possible that taxes will be unresponsive to debt at times, active monetary policy in one regime is not sufficient to insulate the economy against tax shocks in that regime, and may have the unintended consequence of amplifying and propagating the aggregate demand effects of tax shocks.

The paper also considers the implications of policy switching for two empirical issues. First, the "price puzzle" that plagues monetary VARs is a natural outcome of periods when monetary policy fails to obey the Taylor principle and taxes do not respond to the state of government indebtedness. Second, dynamic correlations between fiscal surpluses and government liabilities, which have been interpreted as consistent with Ricardian Equivalence, can be produced by an underlying equilibrium that is non-Ricardian.

Because we are driven to model regime switching by actual policy behavior in the United States, it is useful to review the evidence.

1.1. A Quick Post-WW II History of Regime Change. Many macroeconomists believe that U.S. monetary policy changed regime in late 1979. The view holds that monetary policy changed from a period where increases in inflation were passively accommodated to one where incipient inflation was actively combatted with tighter policy. ${ }^{2}$ Taylor (1999a), Clarida, Gali, and Gertler (2000), and Lubik and Schorfheide (2003b), among others, found that from 1960-1979 the Fed followed an interest rate rule that responded only weakly to inflation, failing to satisfy the Taylor principle. Since the early 1980s, the Taylor principle is satisfied, according to this empirical work. But even the most sanguine observers of recent Fed successes cannot exclude the possibility of a return to the days when monetary policy accommodated inflation, as in Sargent's (1999) analysis of American inflation.

Less well appreciated is the fact that fiscal policy may also have experienced changes in regime. ${ }^{3}$ In some periods, taxes are adjusted passively in response to changing

\footnotetext{
${ }^{2}$ Sargent (1999) and Cogley and Sargent (2002a,b) are consistent with this view, but see Bernanke and Mihov (1998), Sims and Zha (2002), and Hanson (2003) for an alternative view.
} 
debt levels; at other times, tax changes are active attempts to achieve non-budgetary macroeconomic goals.

The history of tax policy illustrates the pendulum swings in policy. In the 1950s taxes were increased three times on the grounds of budget balancing, in large part to finance the Korean War [Ohanian (1997)]. By the 1960s, with the rise of the "new economics," tax changes were initiated primarily as a countercyclical tool [Heller (1967)]. Budget balance had slipped into the background of tax debates. This trend continued for two decades. The resulting explosion in Federal government debt and its associated interest payments shifted priorities once again toward budget balancing, and eventually in the 1980s and 1990s, Presidents Reagan, Bush, and Clinton all signed legislation that raised taxes to reduce budget deficits. By the time the tax cut of 2001 was ratified by Congress, the rationale had shifted from budget concerns to economic stimulus. Both of the last two tax reductions - 2002 and 2003 - were unambiguously motivated by countercyclical objectives. Evidently over the past 50 years fiscal policy behavior has fluctuated between periods when taxes were adjusted in response to the state of government indebtedness and those when other priorities drove tax decisions.

That both monetary and fiscal regimes have fluctuated is confirmed by Favero and Monacelli (2003) who explicitly model regime switching in their estimates of monetary and tax policy rules in the United States. Taylor $(1996,2000)$ and Auerbach (2002) document changes in the responsiveness of taxes to macro conditions, providing further evidence that tax policy rules changed.

Against this history of shifts in policy rules, we use very simple models to take first steps toward examining the implications of the kinds of regime changes that the United States has actually experienced. Although stark, the models highlight that regime switching generates mechanisms that will continue to be present in richer models where the mechanisms are harder to isolate.

\section{Contacts with the Literature}

This paper makes contact with existing work in several areas. Sargent and Wallace (1981) were among the first to emphasize intertemporal aspects of monetary and fiscal policy interactions. With monetary and fiscal policy, there are two policy authorities that jointly determine the price level and ensure the government is solvent. When one policy authority pursues its objective unconstrained by the behavior of the other authority, its behavior is "active," whereas the constrained authority's behavior is "passive." 4

\footnotetext{
${ }^{3}$ For details see Pechman (1987), Poterba (1994), Stein (1996), Steuerle (2002), and Yang (2003).
} 
If policy regime is fixed, active monetary policy coupled with passive fiscal policythe policy mix implicit in the literature on the Taylor principle-produces conventional monetarist and Ricardian predictions of monetary and fiscal policy impacts. In contrast, when active fiscal policy combines with passive monetary policy - the combination associated with the fiscal theory of the price level ${ }^{5}$ - monetary and tax changes generate wealth effects that shift aggregate demand, and policy impacts are non-monetarist and non-Ricardian.

Lucas (1976) taught macroeconomists to think about policy changes in terms of shifts in regime. But Lucas's examples all involve once-and-for-all changes, rather than the on-going process described in the history above. Cooley, LeRoy, and Raymon (1982, 1984), among others, have argued that treating policy as making once-andfor-all choices is logically inconsistent. After all, if policy authorities can contemplate changing regime, then regime is not permanent. If there has been a history of changes in policy regimes, private agents will ascribe a probability distribution over those regimes. Agents' expectations, and therefore their decision rules, will reflect their belief that policy changes are not once-and-for-all. This point resonates especially crisply in the United States, where the policy changes we aim to model are intrinsically temporary; they arose largely because of the personalities of the political players, rather than through the creation of new policy institutions or changes in existing institutions' legal mandates.

Clarida, Gali, and Gertler (2000, p. 149) argue that when the Fed failed to obey the Taylor principle before 1979, it left "open the possibility of bursts of inflation and output that result from self-fulfilling changes in expectations." The possibility of multiple equilibria relies on the implicit assumption that fiscal policy was passive during this period. Woodford (1999) suggests that fiscal policy may have been active during that period, implying that observed inflation emerged from a unique equilibrium. Favero and Monacelli (2003) and Sala (2003) offer empirical evidence that fiscal policy was active and monetary policy was passive in the 1960s and 1970s, supporting Woodford's argument.

All this work is couched in terms of changes in policy regime, and there have been some efforts to incorporate switching policy specifications into dynamic stochastic general equilibrium models to study the fiscal theory of price level determination (FTPL) [Sims (1997), Woodford (1998), Loyo (1999), Mackowiak (2002), Weil (2003), and Daniel (2003)]. But each of these papers considers only one-time changes in regime. In addition, Loyo (1999), Weil (2003), and Daniel (2003) consider only

\footnotetext{
${ }^{4}$ This follows Leeper's (1991) taxonomy.

${ }^{5}$ See, for example, Leeper (1991), Sims (1994), Woodford (1995), and Cochrane (1999).
} 
changes in fiscal regime, holding monetary policy behavior fixed. Given a history of both monetary and fiscal regime switching, it is important to allow both policies to change. This paper generalizes the theoretical literature on monetary and fiscal policy interactions by explicitly modeling regime change as an on-going process. Both one-time changes in regime and changes in only fiscal or monetary policy behavior are special cases of our specification.

There is work that models on-going regime change [Andolfatto and Gomme (2003), Davig (2002, 2003), Leeper and Zha (2003), Schorfheide (2003), and Andolfatto, Hendry, and Moran (2002)]. That work considers only exogenous processes for policy variables that switch regime. This paper makes substantive and technical contributions by extending work on on-going regime change to allow the objects subject to change to be parameters that determine how the economy feeds back to policy choice. This is the first example of which we are aware that allows for regime switching in parameters of endogenous policy rules in an equilibrium model, where the parameters determine existence and uniqueness.

Empirical findings that policy regimes have changed in important ways are difficult to interpret without theory that models regime changes explicitly [Favero and Monacelli (2003) and Sala (2003)]. This paper fills some of the theoretical holes.

Finally, the paper connects to two bodies of empirical work. It offers an interpretation of the price puzzle in monetary VARs that differs from the cost channel put forth by Barth and Ramey (2002) and Christiano, Eichenbaum, and Evans (2001). The paper also provides a counterexample to the empirical inferences drawn by Bohn (1998) and Canzoneri, Cumby, and Diba (2001) about the behavior of fiscal policy in the United States.

\section{An Analytical Example with Regime Switching}

Canzoneri, Cumby, and Diba (2001) (CCD) argue that Ricardian equilibria are, in a certain sense, more general than non-Ricardian equilibria. They make this argument by proving a proposition that states that over time the response of the government surplus to total government liabilities merely needs to be bounded away from zero infinitely often for the equilibrium to exhibit Ricardian Equivalence. The key point is that the private sector must expect taxes to adjust "sooner or later," though the adjustment can be arbitrarily small and infrequent. Because the proposition does not require the fiscal response to be strong enough to make the evolution of government debt stable, the Ricardian equilibria CCD consider are potentially ones with an unbounded debt-output ratio. 
Equilibria with unbounded debt-output ratios may not be the most interesting or relevant ones to consider. And they may be misleading if the impacts of taxes hinge on the unboundedness assumption. Unbounded debt-output ratios are well outside any country's experience, so it is impossible to tell if policy authorities would permit such equilibria to occur. It is quite possible that if a country's policies made its debtoutput ratio appear to grow without limit, the country would undergo fundamental macro policy reforms of the type that neither we nor CCD consider. We assume the political process ensures the debt-output ratio is bounded.

This section presents an analytical example in which policies that satisfy the assumptions of CCD's proposition deliver a non-Ricardian equilibrium that is unique within the set of equilibria with bounded debt-output ratios. Important conclusions appear to hinge on CCD's assumption of unboundedness.

Consider a constant endowment version of Sidrauski (1967), modified to include an interest rate rule for monetary policy and a tax rule for fiscal policy. If government consumption is constant, then in equilibrium the representative agent's consumption, $c$, is also constant, as is the real interest rate. Preferences over consumption and real money balances are logarithmic. This model implies a Fisher equation

$$
1 / R_{t}=\beta E_{t}\left[1 / \pi_{t+1}\right]
$$

where $0<\beta<1$ is the discount factor, $R_{t}$ is the gross nominal interest rate on oneperiod nominal government debt, $\pi_{t+1}$ is the gross inflation rate between $t$ and $t+1$, and the expectation is taken with respect to a set $\Omega_{t}$ that contains information dated $t$ and earlier, including the history of regimes up to $t$. The money demand function is

$$
m_{t}=\frac{R_{t}}{R_{t}-1} c,
$$

where $m_{t}=M_{t} / P_{t}$ is the real value of money balances.

Monetary policy adjusts the nominal interest rate in response to inflation according to the rule

$$
R_{t}=\exp \left(\alpha_{0}+\alpha\left(S_{t}\right) \hat{\pi}_{t}+\theta_{t}\right)
$$

where $\widehat{\pi}_{t} \equiv \ln \pi_{t}, \theta_{t}$ is an i.i.d. shock, $S_{t}$ is the current regime and $\alpha\left(S_{t}\right)$ is a regimedependent parameter. Tax policy follows a rule that adjusts lump-sum taxes in response to the real value of total government liabilities:

$$
\tau_{t}=\gamma_{0}+\gamma\left(S_{t}\right)\left(b_{t-1}+m_{t-1}\right)+\psi_{t}
$$


where $\tau_{t}$ is the level of lump-sum taxes, $b_{t-1}=B_{t-1} / P_{t-1}$ and $m_{t-1}$ are the real values of debt and money at the beginning of period $t$, and $\psi_{t}$ is an i.i.d. disturbance. The response of taxes to liabilities takes on values that depend on the realization of regime. $S_{t}$ obeys an $N$-state Markov chain with transition probabilities $P\left[S_{t}=j \mid S_{t-1}=i\right]=$ $p_{i j}$, where $i, j \in\{1, N\}$.

The government's flow budget identity holds at each date $t \geq 0$ :

$$
\frac{B_{t}+M_{t}}{P_{t}}+\tau_{t}=g+\frac{M_{t-1}+R_{t-1} B_{t-1}}{P_{t}},
$$

given initial nominal liabilities $M_{-1}>0, R_{-1} B_{-1}>0 .{ }^{6}$

Define the expectation error

$$
\eta_{t+1} \equiv \frac{\frac{R_{t}}{\pi_{t+1}}}{E_{t}\left(\frac{R_{t}}{\pi_{t+1}}\right)}=\beta \frac{R_{t}}{\pi_{t+1}}
$$

where the equality comes from using the Fisher equation. Combining (1) and (3) and using (6), the inflation process obeys

$$
\widehat{\pi}_{t+1}=\alpha\left(S_{t}\right) \widehat{\pi}_{t}+\alpha_{0}+\theta_{t}-\widehat{\eta}_{t+1}+\ln \beta .
$$

Let $l_{t}=b_{t}+m_{t}$. Equations (4) and (5) together with (2) imply that government liabilities evolve according to:

$$
l_{t}=\left(\frac{R_{t-1}}{\pi_{t}}-\gamma\left(S_{t}\right)\right) l_{t-1}-\frac{R_{t-1}}{\pi_{t}} c+D-\psi_{t} .
$$

where $D=g-\gamma_{0}$.

Assume that: (i) $E_{t}\left[\gamma_{t+1}\right]=\gamma$; (ii) $\gamma$ satisfies $|1 / \beta-\gamma|>1$; (iii) the inflation process given by (7) is stable in expectation (that is, $E_{t} \pi_{t+k}<\infty$ for all $k$ ). Assumptions (i) and (ii) mean that on average fiscal policy is active and assumption (iii) means that on average monetary policy is passive (the Taylor principle does not hold on average) ${ }^{7}$

Iterate forward on (8) to obtain (for $k \geq 0$ )

$l_{t+k}=\prod_{j=0}^{k}\left(\frac{R_{t-1+j}}{\pi_{t+j}}-\gamma_{t+j}\right) l_{t-1}+\sum_{j=0}^{k} \prod_{i=1}^{k-j}\left(\frac{R_{t-1+i+j}}{\pi_{t+i+j}}-\gamma_{t+i+j}\right)\left(D+\frac{R_{t-1+j}}{\pi_{t+j}} c-\psi_{t+j}\right)$.

\footnotetext{
${ }^{6} \mathrm{By}$ assuming initial government debt is positive, we do not address the criticism that the fiscal theory of the price level falls apart when $B_{-1}=0$. The criticism is made in a perfect foresight model by Niepelt (2001) and countered in a stochastic model with incomplete markets by Daniel (2003).

${ }^{7}$ Appendices $\mathrm{B}$ and $\mathrm{C}$ provide the stability conditions for the inflation process.
} 
To solve (9), take expectations as of $t-1$, apply the law of iterated expectations, and use the Fisher equation. Then we can replace the terms $\frac{R_{t-1+j}}{\pi_{t+j}}$ with $\frac{1}{\beta}$. Under the assumption that $E_{t}\left[\gamma_{t+1}\right]=\gamma,(9)$ becomes

$$
E_{t-1}\left[l_{t+k}\right]=(1 / \beta-\gamma)^{k+1}\left[l_{t-1}-c\left(\frac{1 / \beta-D / c}{1 / \beta-\gamma-1}\right)\right]+c\left(\frac{1 / \beta-D / c}{1 / \beta-\gamma-1}\right) .
$$

Stability in expectation requires that $l_{t-1}=c\left(\frac{1 / \beta-D / c}{1 / \beta-\gamma-1}\right)$, which is positive if $D / c<$ $1 / \beta$. The value of $\eta_{t}$ is obtained from the budget constraint after substituting in the value of $l$ :

$$
\eta_{t}=\beta \frac{\left(1+\gamma\left(S_{t}\right)\right)(1 / \beta-D / c)-(D / c)(1 / \beta-\gamma-1)}{1+\gamma-D / c}+\frac{\beta}{c}\left(\frac{1 / \beta-\gamma-1}{1+\gamma-D / c}\right) \psi_{t} .
$$

Equation (11) is the unique equilibrium mapping from the tax disturbance, $\psi_{t}$, and the realization of the tax feedback parameter, $\gamma\left(S_{t}\right)$, to the forecast error in inflation. The solution for $\eta$ and the stable inflation process, (7), uniquely determine inflation. For an equilibrium of this type to exist, we restrict the parameters to assure that $\eta_{t}$, which is the ratio of two positive numbers, is positive for any realization of $\psi_{t}$. A sufficiently small value for $D / c$, coupled with a sufficiently high bounded negative support for $\psi$ will do the job.

As a concrete example, suppose there are two regimes, $N=2$, and that the policy parameters take on the values

$$
\alpha\left(S_{t}\right)=\left\{\begin{array}{l}
\alpha(1) \text { for } S_{t}=1 \\
\alpha(2) \text { for } S_{t}=2
\end{array} \quad \gamma\left(S_{t}\right)=\left\{\begin{array}{l}
\gamma(1) \text { for } S_{t}=1 \\
\gamma(2) \text { for } S_{t}=2
\end{array} .\right.\right.
$$

Further suppose that $\alpha(1)$ and $\alpha(2)$ are sufficiently small such that, given the transition probabilities, the inflation process, (7), is stable in expectation. The assumption that the tax parameters have constant mean implies

$$
\begin{gathered}
E\left[\gamma_{t+j} \mid S_{t}=1, \Omega_{t}\right]=\gamma(1) p_{11}+\gamma(2) p_{21} \\
=E\left[\gamma_{t+j} \mid S_{t}=2, \Omega_{t}\right]=\gamma(1) p_{12}+\gamma(2) p_{22} \equiv \gamma
\end{gathered}
$$

$j>0$. By assumption $\left|\beta^{-1}-\gamma\right|>1$. If either $\gamma(1)$ or $\gamma(2)$ is positive and jointly they satisfy (12), then the model satisfies CCD's premise that taxes adjust to debt infinitely often. But as (11) makes clear, negative tax disturbances generate wealth effects that raise the inflation rate. The only equilibrium with bounded debt is non-Ricardian.

This does not deny the existence of Ricardian equilibria of the kind that CCD emphasize. But if those equilibria do exist, they must imply debt-output ratios that grow without bound. 


\section{A Computational Model}

We turn now to a variant on the model in section 3, which is less convenient analytically but more closely tied to actual policy behavior. Because the variant does not admit an analytical solution, we use Coleman's (1991) monotone map method to find a fixed point in the economy's decision rules.

4.1. Households. As before, the representative consumer receives a constant endowment each period, $y_{t}=y$, of which a constant $g_{t}=g<y$ is consumed by the government. Agents choose consumption, $c_{t}$, and decide how to allocate portfolio holdings between values of money, $m_{t}=M_{t} / P_{t}$, and bonds, $b_{t}=B_{t} / P_{t}$. The household's problem is:

$$
\max E_{0} \sum_{t=0}^{\infty} \beta^{t}\left[\log \left(c_{t}\right)+\delta \log \left(m_{t}\right)\right]
$$

subject to

$$
c_{t}+m_{t}+b_{t}+\tau_{t}=y+\frac{m_{t-1}}{\pi_{t}}+R_{t-1} \frac{b_{t-1}}{\pi_{t}},
$$

where $\delta>0$. The household takes initial nominal assets as given: $M_{-1}>0, R_{-1} B_{-1}>$ 0 . Expectations at date $t$ are taken with respect to $\Omega_{t}$. Policy is the sole source of uncertainty.

In equilibrium, $c_{t}=c=y-g$ and the first-order necessary conditions reduce to the Fisher equation, (1), and the money demand relation

$$
m_{t}=\delta c\left[\frac{R_{t}}{R_{t}-1}\right] .
$$

The optimal paths for real balances and bonds must also satisfy their respective transversality conditions.

4.2. Policy Specification. The policy specifications in the computational model connect to existing literature and actual policy behavior. The monetary and tax rules are:

$$
\begin{aligned}
R_{t} & =\alpha_{0}\left(S_{t}\right)+\alpha_{1}\left(S_{t}\right) \pi_{t}+\theta_{t} \\
\tau_{t} & =\gamma_{0}\left(S_{t}\right)+\gamma_{1}\left(S_{t}\right) b_{t-1}+\psi_{t}
\end{aligned}
$$


where $S_{t} \in\{1,2\}, \theta_{t} \sim I D N\left(0, \sigma_{\theta}^{2}\right)$ and $\psi_{t} \sim I D N\left(0, \sigma_{\psi}^{2}\right)$. The reaction coefficients take values that depend on regime:

$$
\begin{aligned}
& \alpha_{i}\left(S_{t}\right)=\left\{\begin{array}{l}
\alpha_{i}(1) \text { for } S_{t}=1 \\
\alpha_{i}(2) \text { for } S_{t}=2
\end{array}, \quad \text { for } i=\{0,1\},\right. \\
& \gamma_{j}\left(S_{t}\right)=\left\{\begin{array}{l}
\gamma_{j}(1) \text { for } S_{t}=1 \\
\gamma_{j}(2) \text { for } S_{t}=2
\end{array}, \quad \text { for } j=\{0,1\} .\right.
\end{aligned}
$$

In this economy with perpetually full employment, an interest rate rule for monetary policy is clearly not optimal. If anything, it will reduce private welfare. We employ (16) for two reasons. First, it closely resembles monetary policy rules that have received detailed study in recent years [Taylor (1999b)]. Second, (16) produces features of an equilibrium that will continue to hold in models with frictions in which rules from the general class to which (16) belongs are optimal. Fiscal rules like (17) that make taxes respond to debt (rather than total liabilities, as in (4)) are widely used in model simulations [Bryant, Hooper, and Mann (1993)], analytical studies of monetary and fiscal policy interactions [Leeper (1991), or Sims (1997)], and empirical work [Favero and Monacelli (2003)]. Specification (4) has the conceptually appealing feature that it separates monetary and fiscal policy: an open-market operation that has offsetting effects on $m$ and $b$ does not affect taxes under (4), while it does under (17). Specification (17), however, has the realistic feature that fiscal authorities respond to the state of government debt, rather than the sum of debt and high-powered money.

The government uses a combination of lump-sum taxes, new one-period nominal bonds and money creation to finance government purchases and debt payments and satisfy the government's flow budget identity, (5).

In a fixed-regime version of this model, Leeper (1991) shows that existence and uniqueness depend on the policy feedback parameters. In a linear approximation to the model, a monetary authority that reacts aggressively to inflation, $\left|\alpha_{1} \beta\right|>1$ combined with a fiscal authority that raises taxes sufficiently to cover interest payments and principle on the debt, $\left|\beta^{-1}-\gamma_{1}\right|<1$, imply a locally unique equilibrium consistent with Ricardian equivalence. This policy combination is referred to as active monetary and passive fiscal policy $(\mathrm{AM} / \mathrm{PF}){ }^{8} \mathrm{~A}$ monetary authority that reacts weakly to inflation, $\left|\alpha_{1} \beta\right|<1$ together with a fiscal authority that reacts weakly to

\footnotetext{
${ }^{8}$ Logarithmic preferences make money essential and eliminate Obstfeld and Rogoff's (1983) speculative hyperinflations as potential equilibria. This allows the Taylor principle, coupled with passive tax policy, to deliver uniqueness. As Sims (1997) shows, if money is inessential, this policy mix does not produce a determinant equilibrium.
} 
real debt, $\left|\beta^{-1}-\gamma_{1}\right|>1$, imply a locally unique equilibrium where the path of taxes affects the inflation rate. This policy combination is referred to as passive monetary and active fiscal policy (PM/AF). One version of the fiscal theory of the price level emerges as the special case $\alpha_{1}=\gamma_{1}=0$.

We use the local results from the linearized (fixed-regime) model to guide parameter choices for the non-linear switching model. For most of this paper regime 1 combines active monetary policy with passive fiscal policy (AM/PF): $\left|\alpha_{1}(1) \beta\right|>1$ and $\left|\beta^{-1}-\gamma_{1}(1)\right|<1$. Regime 2 combines passive monetary policy with active fiscal policy $(\mathrm{PM} / \mathrm{AF}):\left|\alpha_{1}(2) \beta\right|<1$ and $\left|\beta^{-1}-\gamma_{1}(2)\right|>1 .^{9}$

Regimes follow a two-state Markov chain governed by the transition matrix

$$
\begin{gathered}
\Pi=\left[\begin{array}{cc}
p_{11} & 1-p_{11} \\
1-p_{22} & p_{22}
\end{array}\right], \\
P\left[S_{t}=j \mid S_{t-1}=i\right]=p_{i j}, \quad \text { where } i, j=1,2
\end{gathered}
$$

and $p_{12} \equiv 1-p_{11}$ and $p_{21} \equiv 1-p_{22} \cdot{ }^{10}$

We assume agents observe current and past realizations of regimes and of exogenous disturbances.

4.3. Competitive Equilibrium. The bounded equilibrium for the economy with regime-switching policy rules is defined as:

Definition 1. Given the state vector $\Phi_{t}=\left\{w_{t-1}, b_{t-1}, \theta_{t}, \psi_{t}, S_{t}\right\}$, where $w_{t-1}=$ $R_{t-1} b_{t-1}+m_{t-1}$, a bounded competitive equilibrium for the economy consists of a continuous decision rule for real debt, $b_{t}=h^{b}\left(\Phi_{t}\right)$, and a continuous pricing function, $\pi_{t}=h^{\pi}\left(\Phi_{t}\right)$, such that

(1) taking sequences $\left\{R_{t}, \tau_{t}, \pi_{t}, \theta_{t}, \psi_{t}, S_{t}\right\}$ as given, the representative agent's optimization problem is solved;

(2) the fiscal authority sets $\tau_{t}$ according to (17) and the monetary authority sets $R_{t}$ according to (16);

(3) the government budget identity, (5), and the aggregate resource constraint, $y_{t}=c_{t}+g_{t}$, are satisfied.

\footnotetext{
${ }^{9}$ The model is specified to ensure that the problems arising from multiple steady state equilibria, which Benhabib, Schmitt-Grohe, and Uribe (2001a,b, 2002) emphasize, cannot occur.

${ }^{10}$ Although our reading of macro policy history and Favero and Monacelli's (2003) estimates suggest that monetary and fiscal policy have not switched synchronously, as a first step we assume that they do. Full non-synchronous switching would allow the economy to evolve for a time under policies that are both passive. A PM/PF mix, if it were expected to last forever, yields indeterminacy of equilibrium. We postpone to later work grappling with the numerical aspects of indeterminacies and sunspots in non-linear models.
} 


\section{A Benchmark Specification}

This section describes the computational aspects of a benchmark specification, including the choice of parameter values, the computation of non-linear impulse response functions, and details about the numerical solution.

5.1. Parameter Selections. Our objective is to obtain qualitative, rather than quantitative, implications from the model, and the parameter values were chosen with that aim in mind. Several parameter choices were based on their implications for the model's deterministic steady state, which we set equal across regimes. We take the model to be at an annual frequency, so we set $\beta=.9615$, implying a 4 percent real interest rate. Output is normalized to 1 and government consumption is 25 percent of GDP. The debt-output ratio is .4 and inflation is 3 percent in the deterministic steady state; both numbers are in the ballpark for post-war U.S. data. In choosing the weight on real money balances in preferences, $\delta$, we sought to make the model's consumption velocity close to U.S. data. ${ }^{11}$ This implied $\delta=.0296$.

The feedback parameters in the policy rules, $\left(\alpha_{1}\left(S_{t}\right), \gamma_{1}\left(S_{t}\right)\right)$, were chosen to correspond to values used in the literature. In regime 1 -active monetary policy and passive fiscal policy - $\alpha_{1}(1)=1.5$, a common value in the Taylor rule literature, and $\gamma_{1}(1)=.275$, implying a very strong response of taxes to debt. In regime 2 -passive monetary policy and active fiscal policy - we chose the rules most often analyzed in the FTPL literature: $\alpha_{1}(2)=0$ and $\gamma_{1}(2)=0$, making both the nominal interest rate and taxes exogenous.

Given the settings for $\left(\alpha_{1}\left(S_{t}\right), \gamma_{1}\left(S_{t}\right)\right)$ and the assumptions on the deterministic steady state values for debt and inflation, the intercept terms for the policy rules, $\left(\alpha_{0}\left(S_{t}\right), \gamma_{0}\left(S_{t}\right)\right)$, are determined.

For the benchmark specification, we make the transition probabilities between regimes equal, with the regimes only moderately persistent. With $p_{11}=p_{22}=.85$, the average regime duration is $6-2 / 3$ years. This duration is briefer than seems plausible, but it makes the differences between regimes clear. ${ }^{12}$

The variances of the $i . i . d$. policy shocks, $\left(\theta_{t}, \psi_{t}\right)$, are fixed across regimes. We set $\sigma_{\theta}^{2}=3.125 e-6$ and $\sigma_{\psi}^{2}=2.05 e-5$. A constant $\sigma_{\psi}^{2}$ implies the same-sized tax shock in each regime: two standard deviations amount to a change in taxes relative to its stationary mean of about 3-1/2 percent. Because of simultaneity between $R_{t}$ and $\pi_{t}$ in the monetary policy rule, a constant $\sigma_{\theta}^{2}$ can imply very different changes in the

\footnotetext{
${ }^{11}$ The average ratio of consumption of non-durables plus services to the real monetary base over 1959-2002 is about 2.4 .

${ }^{12}$ In section 7 we examine the equilibrium's sensitivity to variation in policy settings, including feedback parameters and regime duration.
} 
nominal interest rate from a given shock: a two standard-deviation shock to $\theta_{t}$ lowers $R_{t} 5$ basis points in regime 1 and 35 basis points in regime 2 .

5.2. Non-linear Impulse Response Analysis. The methods of Gallant, Rossi, and Tauchen (1993) are used to assess the dynamic impacts of shocks to fiscal and monetary policy. Impulse response functions report how a shock makes the paths of variables differ from their baseline paths. We take the baseline to be the regimedependent steady state, which is defined as

Definition 2. A regime-dependent steady state, $\{\bar{\pi}(j), \bar{b}(j)\}$, is values for the state vector such that

$$
\left|\left[\pi_{t}, b_{t}\right]^{\prime}\right|-\left|\left[\pi_{t-1}, b_{t-1}\right]^{\prime}\right|<\epsilon
$$

and $S_{t-1}=S_{t}=j$, where $j=\{1,2\}$.

For example, the impact effect of an i.i.d. shock to lump-sum taxes on inflation, conditioning on an $\mathrm{AM} / \mathrm{PF}$ policy (regime 1), is described by

$$
\widehat{\pi}_{t}=h^{\pi}\left(\bar{w}, \bar{b}, 0, \psi_{t}, 1\right)-h^{\pi}(\bar{\Phi}),
$$

where $h^{\pi}(\bar{\Phi})$ is the regime-dependent steady state value for inflation. The paths for inflation and debt are then recursively updated, holding regime constant. The analysis that follows uses derivations analogous to (21) to trace out the impacts of perturbing one shock, holding all other sources of randomness fixed.

5.3. Average versus Marginal Sources of Financing. This paper follows Sargent and Wallace (1981) by emphasizing the fiscal financing consequences of alternative monetary and tax policy rules. We wish to highlight a distinction that does not appear in Sargent and Wallace: there can be an important difference between the average and the marginal source of financing. ${ }^{13}$ In the model's deterministic steady state direct taxation through $\tau$ constitutes over 96 percent of total revenues, leaving seigniorage to cover a little over 3 percent. Although the means of the stochastic steady states across regimes differ slightly from the deterministic steady state values, the message is the same: on average seigniorage is a trivial source of fiscal financing.

\footnotetext{
${ }^{13}$ This distinction is sometimes overlooked. King and Plosser (1985), for example, point to the fact that averaged across time inflation financing is a trivial source of revenues in the United States as suggesting that inflation taxes should also be inconsequential in response to various shocks to the economy. In addition, many observers dispute the relevance of the dynamic policy interactions that Sargent and Wallace describe on the grounds that most developed countries do not rely heavily on seigniorage revenues [King (1995)]. Castro, Resende, and Ruge-Murcia (2003) draw a similar conclusion for OECD countries. See Grilli (1989), Cohen and Wyplosz (1989), and Centre for Economic Policy Research (1991) for related discussions in the context of European Monetary Union.
} 
In regime $1(\mathrm{AM} / \mathrm{PF})$, seigniorage averages about 3.6 percent of total revenues (.99 percent of output), and in regime 2 it averages 3.4 percent (.95 percent of output). These numbers are consistent with the U.S. evidence that King (1995) cites.

There are three distinct marginal sources of financing that exogenous disturbances may generate. The first arises from an instantaneous jump in the price level that revalues existing nominal government liabilities. The other two sources are dynamic, arising from changes in the present values of the primary surplus and seigniorage. Define the present value at date $t$ of the primary surplus from date $t+1$ onward as

$$
x_{t}=\sum_{s=0}^{\infty}\left[\left(\prod_{j=0}^{s} \pi_{t+j+1} R_{t+j}^{-1}\right)\left(\tau_{t+s+1}-g\right)\right]
$$

and of seigniorage as

$$
z_{t}=\sum_{s=0}^{\infty}\left[\left(\prod_{j=0}^{s} \pi_{t+j+1} R_{t+j}^{-1}\right)\left(m_{t+s+1}-m_{t+s} \pi_{t+s}^{-1}\right)\right] .
$$

The government's present value budget identity implies

$$
\frac{B_{t}}{P_{t}}=x_{t}+z_{t}
$$

After taking expectations at date $t$ of both sides of 24, Cochrane (2001b) refers to this relationship as a "debt valuation equation," which he uses to exposit the FTPL. When expected $x_{t}$ and $z_{t}$ are fixed by policy behavior, a bond-financed tax cut must make $P_{t}$ jump to ensure the equilibrium value of debt does not change. This is the instantaneous marginal source of financing.

Under different policy assumptions, exogenous shocks may bring forth expected changes in $x_{t}$ or $z_{t}$. Given the benchmark parameters, when regimes are permanent, i.i.d. shocks to taxes and to monetary policy generate no change in the present value of seigniorage in regime $1(\mathrm{AM} / \mathrm{PF})$, though they do affect the present value of surpluses. Tax shocks in regime $2(\mathrm{PM} / \mathrm{AF})$ leave both $x_{t}$ and $z_{t}$ unchanged, while monetary policy shocks change both $x_{t}$ and $z_{t}$. In contrast, in the switching model only tax disturbances in regime 2 leave the present values in (22) and (23) unchanged. ${ }^{14}$

5.4. Computational Details. It may seem natural to solve the model by first linearizing around the regime-dependent steady states. But in the switching model, policy parameters as well as policy shocks are random variables. For some policies of interest it can turn out that the one-step-ahead forecast error in inflation from the Fisher relation is correlated with future policy parameters. Linear methods fail to

\footnotetext{
${ }^{14}$ If regime 2 set $\gamma_{1}(2)>0$ but small and $0<\alpha_{1}(2)<1$, both present values would change.
} 
capture this correlation, leading the approximations to incorrectly classify existence and uniqueness of equilibrium. Appendices A-C show this in detail for two different linearization methods.

The complete model consists of the first-order necessary conditions from the representative agent's optimization problem, constraints, specification of the policy process, and the transversality conditions on real balances and bonds. The solution method, based on Coleman (1991), conjectures candidate decision rules that reduce the system to a set of non-linear expectational first-order difference equations. The solution consists of two functions that yield values for real debt and inflation given the state.

The decision rule for real debt and the pricing function for inflation are found by substituting the conjectured rules into the complete model, represented by

$$
\begin{aligned}
R_{t} & =\alpha_{0}\left(S_{t}\right)+\alpha_{1}\left(S_{t}\right) h^{\pi}\left(\Phi_{t}\right)+\theta_{t}, \\
\tau_{t} & =\gamma_{0}\left(S_{t}\right)+\gamma_{1}\left(S_{t}\right) b_{t-1}+\psi_{t} \\
m_{t} & =\delta c\left[\frac{R_{t}}{R_{t}-1}\right] \\
R_{t}^{-1} & =\beta\left[E_{t}\left[h^{\pi}\left(\Phi_{t+1}\right)\right]\right]^{-1} \\
h^{b}\left(\Phi_{t}\right)+m_{t}+\tau_{t} & =g+w_{t-1}\left(h^{\pi}\left(\Phi_{t}\right)\right)^{-1}
\end{aligned}
$$

where the future state, $\Phi_{t+1}$, is

$$
\Phi_{t+1}=\left\{w_{t}, b_{t}, \theta_{t+1}, \psi_{t+1}, S_{t+1}\right\},
$$

and $w_{t}=R_{t} b_{t}+m_{t}$.

Substituting (25)-(27) into (28) and (29) and using numerical quadrature to evaluate the triple integral representing expected inflation, reduces the system to two equations in two unknowns, $\pi_{t}$ and $b_{t}$. The system is solved for every set of state variables defined over a discrete partition of the state space, yielding updated approximations to $h^{\pi}\left(\Phi_{t}\right)$ and $h^{b}\left(\Phi_{t}\right)$ at every node in the state space. When evaluating the integral, non-linear interpolation is used to compute inflation for states that lie off the discretized state grid. This procedure is repeated until iterations update the current decision rule by less than some $\epsilon>0$ (set to $1 e-12$ ).

The solution is verified using three criteria. First, residuals for the government budget identity and first-order conditions must be close to zero on each node of the state space. Second, we check that the government's present value budget identity, (24), holds to some tolerance. Third, the unconditional mean of expectational errors must be approximately zero in random simulations. We verify sufficient conditions by observing the solution implies stationary paths for real debt and real balances. The 
solution is verified to be locally unique by randomly perturbing the converged rule and checking that it converges back to the initial rule. Across discrete nodes in the state space, the largest residual is $2 e-15$. The convergence criterion was satisfied at each node.

\section{Computational Results}

This section describes results from the benchmark specification and contrasts those results with predictions from the model with fixed policy regime.

6.1. Impacts of Policy Shocks in Regime 1 (AM/FP). The impacts of monetary and fiscal policy shocks are reported in figures 1 (conditioning on regime 1) and 3 (conditioning on regime 2); solid lines are responses to an i.i.d. tax cut and dashed lines are responses to an i.i.d. monetary easing.

6.1.1. Tax Shocks. In Regime 1, fiscal policy would be Ricardian if policy regime were expected to last forever. A bond-financed tax cut brings forth an expectation of future taxes whose present value exactly equals the increase in the value of debt. With no change in net wealth, demand for goods is unchanged at initial prices and interest rates. Unchanged inflation implies unchanged nominal rates, leaving the present value of seigniorage also unchanged. ${ }^{15}$

When regime can change, agents treat a tax cut as an increase in wealth. Because they place positive probability on switching to regime $2(\mathrm{PM} / \mathrm{AF})$, where taxes are exogenous, the current tax reduction exceeds the expected present value of tax increases in the future. A switch to regime 2 with fixed taxes brings with it a discrete devaluation of government debt through an increase in the price level. Higher wealth increases aggregate demand and the current inflation rate in this economy with a fixed supply of goods [figure 1].

With $\alpha_{1}(1)=1.5$ in regime 1 , monetary policy reacts to the higher inflation rate by raising the nominal interest rate. This creates an expectation that inflation will remain above its stationary level in regime 1 , which is consistent with the anticipated debt devaluation. With the impulse response functions conditional on regime 1 , active monetary policy propagates the transitory tax cut, generating persistently higher inflation and nominal rates. The persistence is so strong that variables remain away from their pre-shock levels over 10 periods after the tax cut.

In periods following the tax cut, taxes increase in a manner suggestive of Ricardian fiscal behavior, as regime 1 policy passively raises taxes when debt increases. But

\footnotetext{
${ }^{15}$ Leeper (1993) reports responses to monetary and tax policy shocks for a closely related fixedregime model under regimes 1 and 2 .
} 
the rise in the value of debt exceeds the present value of these tax increases, with the difference made up by an increase in the present value of inflation taxes.

Inflation exhibits stable responses to policy shocks, as figure 1 shows. Based on intuition derived from single-equation linearized models, this outcome may seem counterintuitive. Conditional on staying in a regime with active monetary policy, in linearized models the Taylor principle makes the inflation equation unstable: after an i.i.d. policy shock, inflation jumps immediately to offset the effect of the policy shock on expected inflation; in the next period, inflation jumps back to its steady-state value. In the non-linear computational results, by contrast, the response of inflation is serially correlated. Moreover, one might think that, since we have a fiscal theory equilibrium, the surprise revaluation of debt must stabilize the debt dynamics in expectation. But in regime 1 monetary policy is active, so the inflation process must also be stabilized. How can both dynamical equations be stabilized by the same revaluation?

The Fisher equation and the monetary policy rule together imply that

$$
\pi_{t+1}=\beta\left(\frac{\alpha_{0}\left(S_{t}\right)+\alpha_{1}\left(S_{t}\right) \pi_{t}}{\eta_{t+1}}\right),
$$

where $\eta_{t+1} \equiv \frac{1 / \pi_{t+1}}{E_{t}\left[1 / \pi_{t+1}\right]}=\beta \frac{R_{t}}{\pi_{t+1}}$, using the Fisher relation to obtain the equality. $\eta$ is a type of expectation error whose economic role is as a revaluation variable. Let $\eta$ be determined by the function $g$

$$
\eta_{t+1}=g\left(\pi_{t}, b_{t}, \theta_{t+1}, \psi_{t+1}, \alpha_{0}\left(S_{t+1}\right), \gamma_{0}\left(S_{t+1}\right)\right) .
$$

Holding regime fixed, after a one-time shock the inflation dynamics of (30) are described by a deterministic system. Taking as given the $g$ function implied by the computational model, we can calculate numerically the system's stability properties in a neighborhood of the regime-dependent steady-state. It turns out that these dynamics are stable for any point in some neighborhood of the steady state.

The stability stands in contrast to the outcome for a linearized model, where the Taylor principle creates post-shock deterministic dynamics that are explosive. The key difference is that in a linearized model the revaluation variable $\eta$ can depend only on $i . i . d$. shocks. In the computational model, $\eta$ depends on lagged inflation and lagged real debt, as well as i.i.d. shocks, as in equation (31). In particular, $\eta$ depends positively on the lagged inflation rate and negatively on lagged real debt. As one might expect, this dependence on past variables stems from the wealth effects present in the regime-switching model. Through the Taylor rule, higher $\pi_{t}$ implies higher $R_{t}$, which leads to higher future interest payments on the debt. Because regime can 
switch, agents expect some of those interest payments to be met with seigniorage in the future. But the impulse response functions in figure 1 condition on staying in regime 1, so taxes are surprisingly high, making aggregate demand and inflation surprisingly low, and $\eta_{t+1}$ larger. A higher value of $b_{t}$, holding $R_{t}$ fixed, makes wealth higher at the beginning of period $t+1$ (because of the likelihood of switching to a regime with exogenous taxes in the future). Higher wealth increases demand and inflation at $t+1$, which lowers $\eta_{t+1}$.

Decision rules in the switching environment differ markedly from the rules when regime is fixed. Figure 2 shows the equilibrium rules for $b_{t}$ and $\pi_{t}$ under AM/PF policies for both fixed and switching regime models. The rules are expressed as functions of $\psi_{t}$ and $\theta_{t}$, holding all other state variables at their regime-dependent steady state values. The lower left panel of the figure illustrates the contemporaneous impacts of taxes on inflation. When regime is permanent Ricardian equivalence makes taxes irrelevant, but taxes matter when regimes can change.

Regime switching also increases the elasticity of real debt to policy disturbances by propagating the shocks' impacts and changing the present values of taxes and seigniorage [right panels of figure 2]. For example, as figure 1 showed, a negative shock to $\psi_{t}$ raises the nominal interest rate and generates an expectation that both direct and inflation taxes will rise in the future, supporting the increase in the current value of debt. Of course, the higher value of debt is associated with a higher present value of surpluses when the switching model conditions on staying in regime 1 where $\gamma_{1}(1)=.275$.

If agents expect tax policy to be non-Ricardian in the future, having the Taylor principle hold in one regime is not sufficient to offset the inflationary impacts of tax disturbances. Indeed, in that regime the Taylor principle may have the unintended effect of giving i.i.d. tax shocks persistent impacts, increasing the variances of demand and inflation.

6.1.2. Monetary Shocks. When regime 1 is fixed, a transitory monetary policy shock creates a one-time increase in inflation by the conventional mechanism of a one-time increase in liquidity. The Taylor principle ensures the nominal interest rate stays fixed. A decline in the value of debt is matched by a decline in the present value of surpluses, guaranteeing that both wealth and future inflation taxes are constant.

Regime switching alters the effects of a transitory monetary easing by expanding liquidity and reducing wealth [figure 1]. Because agents anticipate policy will shift to $\mathrm{PM} / \mathrm{AF}$, they no longer expect lower future taxes to match the decline in debt's value; wealth falls. Lower wealth attenuates the liquidity-induced expansion of demand. Along with the expectation that fiscal policy will switch to exogenous taxes comes 
the expectation of a discrete drop in the inflation rate to revalue debt. The present value of seigniorage and the current nominal interest rate fall accordingly. Lower financial wealth at the beginning of next period, with no new injections of liquidity, reduces inflation in that and subsequent periods.

Note that the monetary shock generates a small "price puzzle": a monetary easing that lowers the nominal interest rate is followed by lower future inflation. As we see below, this pattern emerges because agents perceive there is a chance policy will change to regime 2 in the future.

6.2. Impacts of Policy Shocks in Regime 2 (PM/AF). Regime 2 policy behavior corresponds to the standard FTPL exercise: both taxes and the nominal interest rate are exogenous.

6.2.1. Tax Shocks. A permanent regime 2 is the canonical FTPL exercise. Fixed future taxes and constant current and future interest rates mean that a tax cut cannot be financed by future revenues. At initial interest rates and prices, agents feel wealthier and try to increase their consumption paths. This increase in demand drives up the current price level until the value of debt is returned to its original level and agents are happy with their initial consumption plans. By fixing the interest rate, monetary policy prevents the tax shock from propagating.

Regime switching does not alter the fixed-regime results [figure 3]. The current inflation rate jumps to devalue the newly issued nominal debt; on the margin, the full tax cut is financed by a contemporaneous jump in the price level. An unchanged value of debt is consistent with unchanged present values of taxes and seigniorage. Money growth reacts passively to the higher price level to ensure the money market clears at the fixed nominal interest rate. These effects coincide with those under a fixed $\mathrm{PM} / \mathrm{AF}$ regime because even though agents impute a positive probability to a Ricardian tax rule and a Taylor rule in the future, unchanged real debt and an unchanged present value of surpluses are consistent with such a switch in rules. Indeed, the decision rules as a function of $\psi_{t}$ are identical.

Daniel (2003) considers a once-and-for-all probabilistic shift in tax policy from being strongly responsive to debt to being exogenous. She maintains that monetary policy pegs the nominal interest rate forever. In the present setup, Daniel is assuming the tax rule can switch from regime $1\left(\gamma_{1}(1)>0\right)$ to regime $2\left(\gamma_{1}(2)=0\right)$, while monetary policy is always in regime $2\left(\alpha_{1}(1)=\alpha_{1}(2)=0\right)$. She shows that as long as the probability is positive that taxes will be exogenous in the future, fiscal policy determines the price level. Because the nominal rate is pegged, there is no mechanism in Daniel's model by which a tax shock can be propagated. Even if taxes are currently 
in regime 1, therefore, their impacts are those that the present work attributes to regime 2: a one-time change in the price level that revalues debt.

6.2.2. Monetary Shocks. When regime 2 is fixed, a monetary policy shock at time $t$ lowers the nominal interest rate and induces offsetting portfolio substitutions by agents out of debt and into money. With agents' budget sets unperturbed by the shock, there is no change in aggregate demand or inflation initially. The lower nominal interest rate creates an expectation of lower future inflation and, therefore, seigniorage revenues (supporting the drop in the value of debt). How is the lower expected inflation realized? Although initial changes in real balances and real debt offset each other, the drop in $R_{t}$ makes financial wealth, $w_{t}$, lower at the beginning of period $t+1$. This reduces demand and inflation in that period.

When regime can switch, surprise monetary easing produces a similar pattern of impacts. The only difference is the small contemporaneous uptick in inflation [figure 3], which arises because agents impute a positive probability to switching to regime $1(\mathrm{AM} / \mathrm{PF})$, where expansionary monetary policy raises inflation.

With monetary policy in this model couched in terms of an interest rate rule, the expansionary monetary shock produces a sizeable "price puzzle." As we explore in section 8, this pattern of correlation offers an explanation for the "price puzzle" findings in the monetary VAR literature.

\section{Exploring the Parameter Space}

This section considers alternative parameter settings across two dimensions of the parameter space. First we vary regime duration and report the sensitivity of inflation to taxes when regime $1(\mathrm{AM} / \mathrm{PF})$ prevails. The benchmark settings for the PM/AF regime assume the monetary authority sets interest rates independently of inflation, implying tax reductions are financed entirely by a contemporaneous inflation tax (as in the FTPL). The second dimension we explore is to allow monetary policy to respond weakly to inflation.

7.1. An Active Monetary/Passive Fiscal Regime. As section 6 demonstrated, agents' expectations that regime will switch in the future play a crucial role in determining the impacts of policy disturbances. Here we explore how regime duration affects the result that tax cuts generate wealth effects in regime 1 . The expected duration of a regime is given by

$$
E\left[d_{j} \mid S_{t}=j\right]=\frac{1}{1-p_{j j}},
$$


for $j=\{1,2\}$ and $d_{j}=T-t$, where $S_{t}=S_{t+1}=\cdots=S_{t+T}=j$ and $S_{t+T+1} \neq j$. The benchmark specification assumes that both regimes are relatively persistent: $p_{11}>.5$ and $p_{22}>.5$.

The degree to which tax shocks affect inflation in an $\mathrm{AM} / \mathrm{PF}$ regime depends on the transition matrix. Figure 4 illustrates how the impact of a tax cut on inflation increases as $p_{11} \rightarrow 0$ and $p_{22} \rightarrow 1$. Each decision rule represents different probabilities in the transition matrix, where

$$
\lambda=\frac{E\left[d_{1} \mid S_{t}=1\right]}{E\left[d_{1} \mid S_{t}=1\right]+E\left[d_{2} \mid S_{t}=2\right]}
$$

represents the proportion of time spent in the $\mathrm{AM} / \mathrm{PF}$ regime. As the expected proportion of time spent in the $\mathrm{PM} / \mathrm{AF}$ regime increases, the inflation effects of tax disturbances increase because agents expect to switch to the $\mathrm{PM} / \mathrm{AF}$ regime in the future and then remain there longer relative to the $\mathrm{AM} / \mathrm{PF}$ regime.

As figure 5 illustrates, the transition matrix affects the sensitivity of inflation to a tax cut. The paths for inflation condition on the AM/PF regime and use that regime's steady state as the baseline; the tax cut occurs in period 2. As agents expect to spend relatively more time in the $\mathrm{PM} / \mathrm{AF}$ regime, a tax cut generates a larger increase in inflation on impact and increases the variance of inflation. The larger increase on impact arises from the expectation of a regime change to a more persistent $\mathrm{PM} / \mathrm{AF}$ regime in the near future, which creates a lower expected present value of direct taxes relative to a scenario where the $\mathrm{AM} / \mathrm{PF}$ regime is highly persistent.

7.2. A Passive Monetary/Active Fiscal Regime. In the fixed-regime model, with exogenous taxes and a pegged interest rate, the revaluation of nominal debt following an i.i.d. shock to taxes occurs instantaneously. But even when regime is fixed, transitory tax shocks can generate serially correlated changes in inflation if the monetary authority responds weakly to inflation $\left(\alpha_{1}>0\right)$. This prevents the complete devaluation of nominal debt from occurring in the period of the tax shock. Instead, a tax cut is financed by issuing debt that will be repaid with inflation taxes spread over future periods.

As $\alpha_{1}$ increases, the monetary authority responds more aggressively to inflation and the tax cut causes a larger increase in the interest rate and a smaller contemporaneous rise in inflation. The higher interest rate, along with a higher real value of debt (due to a smaller jump in the current price level), induces substitution from real balances to bonds. As $\alpha_{1}$ increases, so must the present value of seigniorage following a tax cut. However, regardless of the value of $\alpha_{1}$ in the fixed-regime model, the persistence in inflation is quite weak, as the present value of future seigniorage returns to its 
initial level relatively quickly. These effects are illustrated in figure 6 for a tax cut in period 2.

In the switching model, the positive probability of regime change propagates inflation to a much greater degree relative to the fixed-regime model [figure 7]. With $\alpha_{1}(2)>0$, debt rises more in response to a tax cut because agents expect both primary surpluses and seigniorage to adjust in the future. Agents impute positive probability to a change to $\mathrm{AM} / \mathrm{PF}$ policies where the higher value of debt will be repaid with taxes. This generates a negative wealth effect, reducing aggregate demand and lowering the rate of inflation relative to the fixed regime model. These effects are in place until the policy regime changes.

\section{Some Empirical Implications}

This section derives two empirical implications from the theoretical regime-switching environment using time series produced by simulating the benchmark model for 100,000 periods. The simulation allows regime to evolve according to the transition probabilities in $(20)$ and draws $\left(\theta_{t}, \psi_{t}\right)$ from their normal distributions.

8.1. The "Price Puzzle". The "price puzzle" that emerges from many attempts to identify exogenous shifts in monetary policy is well documented [Sims (1992), Eichenbaum (1992), Hanson (2002)]. It was regarded as a puzzle because a monetary expansion that lowers the nominal interest rate is often followed by lower inflation, rather than higher inflation, as many theories would predict. Several papers try to resolve the puzzle by changing identifying assumptions or by expanding the information set on which policy choices are based [Gordon and Leeper (1994), Leeper, Sims, and Zha (1996), Christiano, Eichenbaum, and Evans (1999), Bernanke, Boivin, and Eliasz (2002), Leeper and Roush (2003)].

Another reaction has been that lower inflation following a lower interest rate is not a puzzle at all. To the extent that firms must borrow to finance wage bills and new investment, lower interest rates reduce the costs of production and can lead naturally to lower inflation, at least for some period [Barth and Ramey (2002), Christiano, Eichenbaum, and Evans (2001)].

As suggested in section 6, a positive correlation between the interest rate and future inflation is also a natural outcome of the switching model. It appears subtly under regime $1(\mathrm{AM} / \mathrm{PF})$ and forcefully under regime $2(\mathrm{PM} / \mathrm{AF})$. We now show that if time series data were generated by this setup, one should expect to find that positive interest rate innovations predict higher inflation.

Figure 8 shows the responses of inflation and the nominal interest rate to an orthog-

onalized innovation in the nominal rate. Ordering inflation before the interest rate 
is consistent with much of the VAR work, which treats inflation as predetermined, and is also consistent with estimates of the Taylor rule, which regress the nominal rate on inflation (and potentially other variables). Although the policy disturbances are i.i.d. and the monetary policy rule is purely contemporaneous, the interest rate displays substantial serial correlation. Inflation rises sharply in the short run, and remains above its initial level for 10 periods.

The model's results are consistent with the Hanson's (2002) careful analysis. He finds that the "price puzzle" cannot be solved by the conventional method of adding commodity prices to the Fed's information set. And more to the point for the present work, Hanson finds that the "puzzle" is more pronounced in the period 1960-1979. But Favero and Monacelli (2003) identify that period as one where monetary policy was passive and fiscal policy was active. As figure 3 shows, the model predicts precisely this outcome when conditioning on $\mathrm{PM} / \mathrm{AF}$.

8.2. Surplus-Debt Regressions. A number of authors have computed regressions of budget surpluses and government debt to draw inferences about the source of fiscal financing [Canzoneri, Cumby, and Diba (2001), Bohn (1998), Janssen, Nolan, and Thomas (2001)]. Canzoneri, Cumby, and Diba (CCD), for example, estimate a bivariate VAR with the government surplus and total liabilities. ${ }^{16}$ Their figure 3 (p. 1228) reports that a positive innovation in the surplus is followed by persistently lower liabilities and a surplus that is significantly positive for only two periods. They argue that a Ricardian interpretation of the data is "more plausible" than is a non-Ricardian one, as the increase in the surplus is used to retire debt.

Simulated data from the regime-switching model produce a pattern of correlation strikingly similar to the top panel of CCD's figure. A positive innovation to the surplus produces an immediate and persistent decline in liabilities [figure 9]. ${ }^{17}$ Of course, as figure 1 makes clear, even conditional on current tax policy being Ricardian, tax shocks always generate wealth effects and non-Ricardian outcomes.

Our setup is completely straightforward and plausible. Both a reading of American tax history over CCD's sample period and the corroborating formal statistical evidence that Favero and Monacelli (2003) present support the view that monetary and fiscal policy regimes have switched in a manner that our setup aims to capture.

\footnotetext{
${ }^{16}$ The surplus is defined to include seigniorage and total liabilities are the sum of net government debt and the monetary base.

${ }^{17}$ Given the paucity of independent disturbances in the model and the simple form of the tax rule, which excludes any contemporaneous response to other variables, in the reverse Choleski orderingliabilities, surplus - an orthogonalized innovation to the surplus has no predictive value for liabilities.
} 


\section{Concluding Remarks}

In most countries monetary and fiscal authorities cannot credibly commit to always follow either active monetary policy and passive fiscal policy or passive monetary policy and active fiscal policy. If, as a consequence, private agents place probability mass on both kinds of regimes, then something like the regime-switching environment that we model will apply. That environment makes wealth effects - from both monetary and tax policy disturbances - important components of policy impacts.

The implications of this switching setup raise some doubts about two pillars of recent policy analysis. First, because tax changes have wealth effects, even if the prevailing regime combines the Taylor principle for monetary policy with taxes that respond strongly to debt, Ricardian equivalence may be a misleading benchmark. Second, if the Taylor principle holds in only one regime, it can actually be destabilizing in the sense that it propagates disturbances and can increase the variance of aggregate demand and inflation.

There are at least two dimensions along which to extend the current framework. Is it possible for both policy authorities to act passively in one regime, yet have the price level uniquely determined? The analytical example in section 3 shows this is possible. The current computational approach must be modified to deliver and appropriately characterize a solution with multiple equilibria or sunspots, as Lubik and Schorfheide (2003a) have done for linear models. The second extension addresses the question: how "big" are the fiscal effects when the current regime is AM/PF? To address this, we need a carefully calibrated model with frictions, possibly of the kind in the workhorse New Keynesian model extended to include long-term government debt as in Cochrane (2001a). In the New Keynesian model monetary policy has more conventional macro effects, in addition to the fiscal financing effects this paper analyzes. With such a model in hand, we could also extract a more complete set of empirical implications. 


\section{Appendix A. Why Linear Methods Fail}

This appendix examines the suitability of various linearization approaches to solving the regime-switching model. Our conclusion is that none of these linearization approaches can be expected to give an accurate characterization of the stability of the full non-linear system in all of the cases of interest to us. This conclusion is somewhat surprising, given the nearly linear dynamics of the full system. Essentially, linearized models miss the role of the endogenous expectation error in determining the long-run behavior of the system. Since the qualitative properties of the dynamics are determined by the system's long-run behavior, these linearized models fail to present an accurate picture of it. In particular, they may fail to classify existence and uniqueness of equilibrium correctly.

To get an intuitive sense of the problem with linearized models, consider first a straightforward linearization around a deterministic steady-state associated with one of the regimes. For the next few paragraphs, we will work with a simplified version of the model, in which seigniorage is identically zero. The government budget identity is therefore

$$
b_{t}=\frac{R_{t-1} b_{t-1}}{\pi_{t}}-\gamma_{1 t} b_{t-1}+g-\gamma_{0 t}-\psi_{t},
$$

where $\left(\gamma_{0 t}, \gamma_{1 t}\right)$ are the regime-dependent parameters of the tax rule, $\left(\gamma_{0}\left(S_{t}\right), \gamma_{1}\left(S_{t}\right)\right)$.

Define the expectation error $\eta_{t}=\frac{1}{\pi_{t}} / E_{t-1}\left[\frac{1}{\pi_{t}}\right]$. Using this definition and the Fisher equation, the government budget identity can be re-written as

$$
b_{t}=\left(\frac{\eta_{t}}{\beta}-\gamma_{1 t}\right) b_{t-1}+g-\gamma_{0 t}-\psi_{t}
$$

The linearized version of this equation is

$$
\Delta b_{t}=\left(\frac{1}{\beta}-\gamma_{1}\right) \Delta b_{t-1}+g-\Delta \gamma_{0 t}-\psi_{t}+\frac{b}{\beta} \Delta \eta_{t}-b \Delta \gamma_{1 t}
$$

where $\Delta b \equiv b_{t}-b$, and $b$ is the steady-state value of real bonds under one of the regimes.

In the single-regime version of the model, the expectation error is i.i.d. and, therefore, the linearized version accurately captures the stability properties of the model. (See end of appendix C for proof.) However, in the full non-linear regime-switching model, the expectation errors $\eta_{t}$ are correlated with $\gamma_{1 t+k}, k>0$. Consequently, $\eta_{t}$ cannot be replaced by $1 / \beta$ in expectations of the form $E_{t} \prod_{k=1}^{\infty}\left(\frac{\eta_{t+k}}{\beta}-\gamma_{1 t+k}\right)$, and, in general, the long-run properties of the linearized model will be different from those 
of the full non-linear model, as the long-run behavior is governed by the expected value of such products. ${ }^{18}$

Now consider an alternative linearization approach. Since the equilibrium policy functions in this model appear to be nearly linear, one might imagine that a statecontingent linearization approach would be successful in reproducing the long-run properties of the full system. In this case, at each date we linearize around the steady-state associated with the regime holding at that date. The resulting randomcoefficients equation is

$$
\Delta b_{t}=\left(\frac{1}{\beta}-\gamma_{1 t}\right) \Delta b_{t-1}+g-\gamma_{0 t}-\psi_{t}+\frac{b}{\beta} \Delta \eta_{t} .
$$

Again, when $\eta$ is deviates significantly from its unconditional mean of unity, the longrun dynamics of the random-coefficient models may fail to represent the stability properties of the full system.

To get a sense of the importance of this possibility, we can compare the results of the linearized models to the full non-linear model for special parameter values for which it is possible to solve the full model exactly. Suppose that monetary policy obeys the rule

$$
R_{t}=\exp \left(\alpha_{0 t}+\alpha_{1 t} \pi_{1 t}+\theta_{t}\right)
$$

Using the Fisher equation, and using the definition of the endogenous expectation error, the dynamics for inflation can be written as

$$
\widehat{\pi}_{t+1}=\alpha_{1 t} \widehat{\pi}_{t}+\theta_{t}+\alpha_{0 t}+\ln \beta-\widehat{\eta}_{t+1},
$$

where ${ }^{\wedge}$ denotes the natural log of the variable.

In appendix B, we show how to determine some long-run properties of this difference equation. For certain parameter values it will turn out that imposing stability on the inflation process is sufficient to determine the mapping between inflation and the exogenous shocks. These are the determinate Ricardian equilibria of this model. Having solved for $\pi$, we can then obtain an expression for the endogenous expectation error $\eta$.

Now return to the government budget identity (this time with seigniorage):

\footnotetext{
${ }^{18}$ This possibility precludes using many of the standard second-order accurate expansions available in the literature. Typically, it is an assumption of these methods that the first-order linearization accurately determines the long-run behavior of the system and this assumption is not necessarily satisfied for our model [Kim, Kim, Schaumberg, and Sims (2003), Schmitt-Grohe and Uribe (2004)].
} 


$$
b_{t}=\left(\frac{\eta_{t}}{\beta}-\gamma_{1 t}\right) b_{t-1}+\Upsilon_{t} \text {, }
$$

where $\Upsilon_{t} \equiv \frac{m_{t-1}}{\pi_{t}}-m_{t}+g_{t}-\gamma_{0 t}-\psi_{t}$. The solution for $\pi$ implies that inflation depends only on the current regime $S_{t}$ and realization of the monetary policy shock, $\theta_{t}$. Therefore, $\Upsilon_{t}$ depends only on current and lagged $\theta$ and $S$. Appendix $\mathrm{C}$ shows that the stability of this equation can be determined because $\eta$ has been determined by monetary policy behavior.

In Ricardian equilibria, we can compare the results of the full non-linear model with those of the straightforward linearization around a single steady state. Results are predictably poor and we will not describe them in detail. More interestingly, we can also compare the random-coefficients linearization with the non-linear model. With the random-coefficients model, however, the only qualitative difference between the two models arises in results concerning the stability of the process for government debt: the random-coefficients model may suggest stability when the non-linear model is not stable and vice-versa.

As a baseline, consider the model with $\gamma_{1}(1)=.275$ and $\gamma_{1}(2)=0, p_{11}=p_{22}=.99$, $\alpha_{0}(1)=-.5, \alpha_{0}(2)=.5$. With this setting, the two linearization schemes report that the bond dynamics are stable if inflation dynamics are. However, such is not the case in the non-linear system. Figures 10-12 report the results of varying $\alpha_{1}$ systematically between 1 and 5. The lightly-shaded areas represent regions identified as Ricardian by both linear methods and by the exact solution to the non-linear system; in this area, linear methods are accurate. Areas shaded in the middle tone are regions of the parameter space that do not support an equilibrium in the non-linear system, but which are equilibria for the linearized system: linear methods fail in this area. Finally, dark regions are areas that, according to the non-linear model, lie outside of the Ricardian space, including non-Ricardian and indeterminate equilibria.

As is apparent from figure 10, with the baseline settings there is a substantial region in which the linearized methods fail to capture the long-run behavior of the system, even though the dynamics conditional on regime are nearly linear. Intuitively, these results arise because the regimes are long-lived, while inflation behavior may differ substantially across regimes. Say, for example, that inflation is much higher in regime 1 than in 2 . Then, when the system switches from regime 1 to 2 , the inflation rate falls and so $\eta$ is large. Moreover, while in regime 2, the inflation rate is persistently and substantially below expectations, since households form their expectations taking into account the possibility of switching back into the high inflation regime 1 . The growth rate of debt is therefore higher than the ex ante real interest rate, at the 
same time that taxes fail to respond to lagged debt. A linearized model with statecontingent coefficients recognizes that debt is explosive in this regime. However, it may not accurately reflect the covariance between interest payments on debt and tax policy and, hence, may misclassify the stability properties of debt.

To gauge the sensitivity of the model to these effects, we varied several parameters of the baseline, including the persistence of the regimes, the standard deviations of the shocks and the intercept terms in the monetary policy rule. ${ }^{19}$ Results of these variations are presented in figures 11-12. Reducing the persistence of the regimes leads to smaller differences in inflation behavior between regimes. Correspondingly, the forecast errors, on average, are not as large, while also not as informative about future tax policy, reducing the correlation between $\eta_{t}$ and $\gamma_{1 t+k}, k>0$. Linear methods then are quite successful in tracking the long-term behavior of the system, as shown in figure 11, which increases the transition probability to .70. Increasing the gap between the intercepts in the two regimes increases the spread in inflation rates across regimes and for similar reasons the performance of linear models becomes commensurately poor. (Figure 12 presents results from a run with the intercepts set at 1 and -1 . The region of the parameter space over which the linear model mis-characterizes the long-run behavior of the model is much larger than the corresponding region for the baseline.)

Nevertheless, given our wish to explore the parameter space over fairly broad regions (including non-Ricardian regions) and with relatively persistent regimes, the linearized models are clearly not suitable. With widely separated, persistent regimes, the expected growth rate of debt is significantly affected by much lower-than-expected (or higher-than-expected) inflation rates. Neither of the linearization approaches matches this feature of the non-linear model, and so cannot match its dynamics in general.

\section{Appendix B. Stability Properties of Random-Coefficient Linear MODELS}

For our purposes, it is sufficient to consider the stability properties of a simple univariate model of the following form:

$$
x_{t}=a\left(S_{t-1}\right) x_{t-1}+\xi_{t-1}+\Psi \eta_{t}
$$

where $a\left(S_{t-1}\right)$ follows an $M$-state Markov chain, $\xi_{t}$ is an exogenous shock process possibly depending on both the state of the Markov chain and on $Q$ additional i.i.d.

\footnotetext{
${ }^{19}$ Altering the variance of the $i . i . d$. shock does not have a very dramatic impact on the performance of the linear model. Therefore, we do not display a graph for this case.
} 
processes $\Theta_{t}$ and $\eta_{t}$ is an endogenous expectation error satisfying the restriction $E_{t} \eta_{t+1}=0$. Let the transition matrix of the Markov chain be given by $\Pi$, where $\Pi_{i j}=\operatorname{prob}\left(s_{t+1}=i \mid s_{t}=j\right)$. Finally, the expectation $E_{t}$ is taken with respect to the time $t$ information set $\left\{x_{t-j}, S_{t-j}, \xi_{t-j}, \zeta_{t-j} \mid j \geq 0\right\}$, where $\zeta$ represents a nonfundamental ("sunspot") shock.

We are interested in the behavior of $E_{t} x_{t+T}$ as $T$ becomes large. Iterating forward on the model shows that

$$
E_{t} x_{t+T}=E_{t}\left(\prod_{j=0}^{T-1} a_{t+j}\right) x_{t}+E_{t} \sum_{j=1}^{T}\left(\prod_{k=0}^{T-j-1} a_{t+k+j}\right)\left(\xi_{t+j-1}+\Psi \eta_{t+j}\right),
$$

where $a_{t+j}$ denotes $a\left(S_{t+j}\right)$. This expectation can be calculated explicitly using the following recursion relation:

$E_{t}\left[\prod_{j=0}^{T} a_{t+j} \mid S_{t}=k\right]=\sum_{l=1}^{M} E_{t+1}\left[\prod_{j=0}^{T-1} \alpha_{t+j} \mid S_{t+1}=l\right] a\left(S_{t}=k\right) \cdot \operatorname{prob}\left(S_{t+1}=l \mid S_{t}=k\right)$,

for $k \in\{1, M\}$.

Define the matrix $\Gamma(a)$ by $\Gamma_{i j} \equiv a(j) \cdot \operatorname{prob}\left(S_{t+1}=i \mid S_{t}=j\right)$ and let the symbol $a_{t}^{(l)}=\prod_{j=0}^{l} a_{t+j}$. Now define the vector

$$
E_{t}\left(a_{t}^{(l)} \mid \bullet\right) \equiv\left(E_{t}\left[\prod_{j=0}^{l} a_{t+j} \mid S_{t}=1\right], \ldots, E_{t}\left[\prod_{j=0}^{l} a_{t+j} \mid S_{t}=M\right]\right),
$$

so that $\operatorname{dim}\left(E_{t}\left(a_{t}^{(l)} \mid \bullet\right)\right)=1 \times M$. With this notation, the previous recursion relation can be written $E_{t}\left(a_{t}^{(l)} \mid \bullet\right)=E_{t}\left(a_{t}^{(l-1)} \mid \bullet\right) \Gamma(a)$. Accordingly, $E_{t}\left(a_{t}^{(l)} \mid \bullet\right)=\omega \Gamma^{l}(a)$, where $\omega$ is a $1 \times M$ vector of ones and $\Gamma^{l}(a)$ denotes a matrix product.

From this relation, it follows that for $j>1$,

$$
\begin{aligned}
& E_{t}\left(a_{t+j}^{(l)} \xi_{t+j-1} \mid S_{t}=m\right)= \\
& \sum_{n=1}^{M} \operatorname{prob}\left(S_{t+j-2}=n \mid S_{t}=m\right) \sum_{k=1}^{M} E_{t+j-2}\left(\xi_{t+j-1} \mid S_{t+j-1}=k, S_{t+j-2}=n\right) \\
& \cdot \operatorname{prob}\left(S_{t+j-1}=k \mid S_{t+j-2}=n\right) \\
& \cdot \sum_{p=1}^{M} E_{t}\left(a_{t+j}^{(l)} \mid S_{t+j}=p\right) \cdot \operatorname{prob}\left(S_{t+j-1}=k \mid S_{t+j}=p\right)
\end{aligned}
$$

and therefore

$$
E_{t}\left(a_{t+j}^{(l)} \xi_{t+j-1} \mid \bullet\right)=\omega \Gamma^{l}(a)\left(\Pi \mu \Pi^{j-2}\right)
$$

where $\mu_{i j} \equiv E_{t}\left(\xi_{t+1} \mid S_{t+1}=i, S_{t}=j\right) \cdot \operatorname{prob}\left(S_{t+1}=i \mid S_{t}=j\right)$. 
For $j=1, E_{t}\left(a_{t+1}^{(l)} \xi_{t} \mid S_{t}=m\right)=\xi_{t} \omega \Gamma^{l}(a) \Pi$.

Finally, the endogenous expectation errors can be handled as follows. Consider terms of the form $d\left(S_{t}\right) \eta_{t}$. Then define the basis random variables $\chi_{j}\left(S_{t}\right)$ associated with the Markov state $S_{t}$, which are defined so that $\chi_{j}\left(S_{t}\right)=1$ if $S_{t}=j$ and 0 otherwise.

Project $d\left(S_{t}\right) \eta_{t}$ onto the $\chi_{j}$ and $\Theta_{t}$, the $Q$ additional $i . i . d$. processes:

$$
d\left(S_{t}\right) \eta_{t}=\sum_{n=1}^{M} a_{n} \chi_{n}\left(S_{t}\right)+\sum_{l=1}^{Q} b_{l} \Theta_{l t}+\varepsilon_{t},
$$

where $\varepsilon_{t}$ is uncorrelated with the $\chi_{j}$ and $\Theta_{t}$. Note that $E_{t} a_{t+j}^{(l)} \mid S_{t}=m$ is measurable with respect to $S_{t}$, so must be expressible as a linear combination of the $\chi_{j}$. It follows that

$$
E_{t}\left[a_{t+j+1}^{(l)} \Psi d\left(S_{t+j}\right) \eta_{t+j} \mid S_{t}\right]=E_{t}\left[a_{t+j+1}^{(l)} \Psi d\left(\widetilde{\left.S_{t+j}\right) \eta_{t+j}} \mid S_{t}\right]\right.
$$

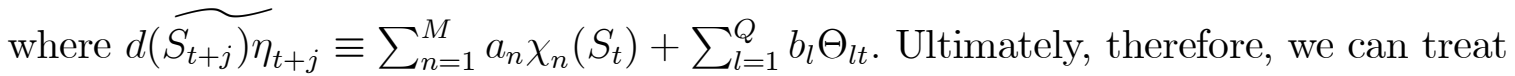
the expectation errors just as we treat the $\xi$, since any dependence on the sunspot shocks $\zeta$ drops out of the expectations of interest.

From here on, let us assume that $\Gamma$ and $\pi$ have $M$ distinct non-zero eigenvalues. Further, let $x(i), i=1 \ldots M$, be the state-contingent mapping of the i.i.d shocks into stable solutions of the difference equation, at time $t$. Finally, define $X \equiv \operatorname{diag}(x(1) \ldots x(M))$, a matrix with the $x(i)$ on its diagonal. With these recursion relations, write

$$
E_{t} x_{t+k}=\omega\left(\Gamma(a)^{k}\left(X+\xi / a\left(S_{t}\right)\right)+\sum_{j=1}^{k} \Gamma^{k-j}(a)\left(\eta \Pi^{-1}+\Pi \mu \Pi^{-2}\right) \Pi^{j}\right) .
$$

Now decompose $\Gamma$ and $\Pi$ into linear combinations of projectors onto their eigenvectors: $\Gamma(a)=\sum_{j=1}^{M} \lambda_{j} P_{j}(\Gamma(a))$ and $\Pi=\sum_{j=1}^{M} \phi_{j} P_{j}(\Pi)$. Then the sum over future shocks can be calculated explicitly to arrive at

$E_{t} x_{t+k}=\omega \sum_{m=1}^{M} P_{m}(\Gamma(a))\left[\lambda_{m}^{k} \cdot\left(X+\frac{\xi}{a\left(S_{t}\right)}\right)+\sum_{n=1}^{M}\left(\frac{\lambda_{m}^{k}-\phi_{n}^{k}}{\lambda_{m}-\phi_{n}}\right)\left(\eta \Pi^{-1}+\Pi \mu \Pi^{-2}\right) P_{n}(\Pi)\right]$.

Therefore, the long-run expected properties of $x$ are characterized by the number of explosive roots of $\Gamma$.

\section{Appendix C. Solving a Ricardian Model}

From the Fisher equation and the monetary policy rule, we have that

$$
1 / R_{t}=\beta E_{t} 1 / \pi_{t+1}=\exp \left(-\alpha_{1 t} \pi_{t}-\alpha_{0 t}-\theta_{t}\right),
$$


where $\theta_{t}$ is i.i.d. Defining

$$
\eta_{t+1}=\frac{1 / \pi_{t+1}}{E_{t} 1 / \pi_{t+1}}
$$

we can rewrite these equations in logs as

$$
\widehat{\pi}_{t+1}=\alpha_{1 t} \widehat{\pi}_{t}+\theta_{t}+\alpha_{0 t}+\ln \beta-\widehat{\eta}_{t+1} .
$$

In this case, $\widehat{\eta}$ is not mean-zero, as is apparent from its definition. Therefore, we decompose $\widehat{\eta}$ into its mean and deviations from the mean: $\widehat{\eta}_{t+1}=\widetilde{\eta}_{t+1}+E_{t} \widehat{\eta}_{t+1}$. Because the monetary policy shock is i.i.d., the mean is purely dependent on the Markov state $S_{t}$. From here on, let $\nu_{t}\left(S_{t}\right)=E_{t} \widehat{\eta}_{t+1}$.

In terms of the formalism from the previous section, we take $x_{t}=\hat{\pi}_{t}$ and $\alpha_{1 t}=$ $a_{t}$. For the sake of convenience, consider the case in which the intercept $\alpha_{0 t}=0$. Written in this form, inflation dynamics are of the form described in Appendix B, and, therefore, stability in expectation requires that, for every explosive root $\lambda_{m}$,

$$
\omega P_{m}(\Gamma)\left(X+\sum_{n=1}^{2} \phi_{n}\left\{\frac{\theta_{t}}{\lambda_{m}}+\frac{\eta \Pi^{-1}}{\lambda_{m}-\phi_{n}}\right\} P_{n}(\Pi)\right)=0,
$$

where, as above, $X$ denotes the initial state-contingent values of the log-inflation process.

The operator $Q_{m} \equiv \sum_{n=1}^{2} \xi_{n} \frac{P_{n}(\Pi)}{\lambda_{m}-\phi_{n}}$ is invertible, so, assuming that both roots of $\Gamma\left(\alpha_{1}\right)$ are explosive, we can write

$$
\sum_{m=1}^{2} \omega P_{m}\left(\Gamma\left(\alpha_{1}\right)\right)\left(X+\sum_{n=1}^{2} \phi_{n} \frac{\theta_{t}}{\lambda_{m}} P_{n}(\Pi)\right)\left\{\sum_{n=1}^{2} \frac{\lambda_{m}-\phi_{n}}{\phi_{n}} P_{n}(\Pi)\right\}=0
$$

since $\omega \eta=0$. This leads to the following sequence of implications:

$$
\begin{gathered}
\Rightarrow \sum_{m=1}^{2} \omega P_{m}\left(\Gamma\left(\alpha_{1}\right)\right)\left\{X \cdot \sum_{n=1}^{2} \frac{\lambda_{m}-\phi_{n}}{\phi_{n}} P_{n}(\Pi)+\sum_{n=1}^{2} \frac{\lambda_{m}-\phi_{n}}{\lambda_{m}} \theta_{t} P_{n}(\Pi)\right\}=0 \\
\Rightarrow \sum_{m=1}^{2} \omega P_{m}\left(\Gamma\left(\alpha_{1}\right)\right) \sum_{n=1}^{2}\left\{X \frac{1}{\phi_{n}}+\frac{1}{\lambda_{m}} \theta_{t}\right\}\left(\lambda_{m}-\phi_{n}\right) P_{n}(\Pi)=0 \\
\Rightarrow \sum_{m=1}^{2} \omega P_{m}\left(\Gamma\left(\alpha_{1}\right)\right)\left\{X \cdot\left(\Pi^{-1} \lambda_{m}-I\right)+\theta_{t}\left(I-\Pi / \lambda_{m}\right)\right\}=0 \\
\left.\Rightarrow \omega\left\{\Gamma\left(\alpha_{1}\right) \cdot X \cdot \Pi^{-1}-X\right)+\theta_{t}\left(I-\Gamma\left(a_{1}\right)^{-1} \Pi\right)\right\}=0
\end{gathered}
$$

Now expand this expression to yield 


$$
\omega\left(\Pi\left(\begin{array}{cc}
\alpha_{1}(1) \widehat{\pi}(1) & 0 \\
0 & \alpha_{1}(2) \widehat{\pi}(2)
\end{array}\right) \Pi^{-1}-X\right)+\left(1-1 / \alpha_{1}(1), 1-1 / \alpha_{1}(2)\right) \theta_{t}=0 .
$$

Finally, after some further algebra with this expression, we can obtain explicit solutions for the inflation function. In this case, the inflation function is very simple: $\hat{\pi}\left(S_{t}\right)=-\theta_{t} / \alpha_{1}\left(S_{t}\right)$.

With the intercept term, we would have obtained $\hat{\pi}\left(S_{t}\right)=-\theta_{t} / \alpha_{1}\left(S_{t}\right)+\Delta\left(S_{t}\right)$, where $\Delta\left(S_{t}\right)$ depends on the still-undetermined $E_{t} \widehat{\eta}_{t+1}$. This term can be determined by imposing the condition that $E_{t} \eta_{t+1}=1$.

Substituting the result for $\hat{\pi}\left(S_{t}\right)$, we have

$$
\begin{gathered}
\beta E_{t}\left\{\exp \left(-\widehat{\pi}_{t+1}+\alpha_{1}\left(S_{t}\right) \pi_{t}+\theta_{t}+\alpha_{0}\left(S_{t}\right)\right)\right\}=1 \\
\Rightarrow \beta E_{t}\left\{\exp \left(\frac{\theta_{t+1}}{\alpha_{1}\left(S_{t+1}\right)}-\Delta\left(S_{t+1}\right)+\alpha_{1}\left(S_{t}\right) \Delta\left(S_{t}\right)+\alpha_{0}\left(S_{t}\right)\right)\right\}=1
\end{gathered}
$$

If $\theta \sim N(0, \sigma)$, then

$$
E_{t}\left\{\exp \left(\frac{\theta_{t+1}}{\alpha_{1}\left(S_{t+1}\right)}\right) \mid S_{t+1}, S_{t}\right\}=\exp \left(\frac{\sigma}{2\left[\alpha_{1}\left(S_{t+1}\right)\right]^{2}}\right)
$$

and therefore

$$
\beta E_{t}\left\{\exp \left(\frac{\sigma}{2\left[\alpha_{1}\left(S_{t+1}\right)\right]^{2}}-\Delta\left(S_{t+1}\right)+\alpha_{1}\left(S_{t}\right) \Delta\left(S_{t}\right)+\alpha_{0}\left(S_{t}\right)\right)\right\}=1 .
$$

This condition, for each initial $S_{t}$, is sufficient to determine $\Delta\left(S_{t}\right)$.

Once the expectations errors $\eta$ have been determined, the long-run properties of the bond dynamics can be derived using a variation of the methods in Appendix B. When steady-state inflation rates are different across regimes, the relevant eigenvalues are those associated with the matrix

$$
\left(\begin{array}{ll}
\left(\frac{\eta(1,1)}{\beta}-\gamma_{1}(1)\right) \Pi_{11} & \left(\frac{\eta(1,2)}{\beta}-\gamma_{1}(1)\right) \\
\left(\frac{\eta(2,1)}{\beta}-\gamma_{1}(2)\right) & \Pi_{12} \\
\Pi_{21} & \left(\frac{\eta(2,2)}{\beta}-\gamma_{1}(2)\right) \\
\Pi_{22}
\end{array}\right) .
$$

When $\gamma_{1}$ is independent of regime, however, the law of iterated expectations implies that

$$
E_{t} \prod_{j=1}^{k}\left(\frac{\eta_{t+j}}{\beta}-\gamma_{1}\left(S_{t+j}\right)\right)=\left(1 / \beta-\gamma_{1}\right)^{k}
$$


This result holds when the conditional mean of $\gamma_{1}$ is independent of the initial state. Thus, under these circumstances, the state-contingent linearization scheme will perfectly capture the long-run behavior of the full non-linear system. 


\section{REFERENCES}

Andolfatto, D., and P. Gomme (2003): "Monetary Policy Regimes and Beliefs," International Economic Review, 44(1), 1-30.

Andolfatto, D., S. Hendry, and K. Moran (2002): "Inflation Expectations and Learning about Monetary Policy," Bank of Canada Working Paper No. 2002-30.

Auerbach, A. J. (2002): "Is There a Role for Discretionary Fiscal Policy?," in Rethinking Stabilization Policy: Proceedings of a Symposium Sponsored by the Federal Reserve Bank of Kansas City, pp. 109-150.

Barth, M. J., and V. A. Ramey (2002): "The Cost Channel of Monetary Transmission," in NBER Macroeconomics Annual 2001, ed. by B. S. Bernanke, and K. Rogoff, pp. 199-239. MIT Press, Cambridge.

Benhabib, J., S. Schmitt-Grohe, and M. Uribe (2001a): "Monetary Policy and Multiple Equilibria," American Economic Review, 91(1), 167-186.

- (2001b): "The Perils of Taylor Rules," Journal of Economic Theory, 96(1-2), $40-69$.

- (2002): "Avoiding Liquidity Traps," Journal of Political Economy, 110(3), $535-563$.

Bernanke, B. S., J. Boivin, And P. Eliasz (2002): "Measuring the Effects of Monetary Policy: A Factor-Augmented Vector Autoregressive (FAVAR) Approach," Mimeo, Princeton University.

Bernanke, B. S., and I. Mihov (1998): "Measuring Monetary Policy," Quarterly Journal of Economics, 113(3), 869-902.

Bonn, H. (1998): "The Behavior of U.S. Public Debt and Deficits," Quarterly Journal of Economics, 113(August), 949-963.

Bryant, R. C., P. Hooper, and C. L. Mann (eds.) (1993): Evaluating Policy Regimes: New Research in Empirical Macroeconomics. The Brookings Institution, Washington, D.C.

Canzoneri, M. B., R. E. Cumby, and B. T. Diba (2001): "Is the Price Level Determined by the Needs of Fiscal Solvency?," American Economic Review, 91(5), 1221-1238.

Castro, R., C. Resende, and F. J. Ruge-Murcia (2003): "The Backing of Government Debt and the Price Level," Mimeo, Universite de Montreal.

Centre for Economic Policy Research (1991): Monitoring European Integration: The Making of Monetary Union. CEPR Annual Report, London.

Christiano, L. J., M. Eichenbaum, and C. L. Evans (1999): "Monetary Policy Shocks: What Have We Learned and to What End?," in Handbook of Macroeconomics, ed. by J. B. Taylor, and M. Woodford, vol. 1A, pp. 65-148. Elsevier Science, 
Amsterdam.

(2001): "Nominal Rigidities and the Dynamic Effects of a Shock to Monetary Policy," Mimeo, Northwestern University.

Clarida, R., J. Gali, and M. Gertler (2000): "Monetary Policy Rules and Macroeconomic Stability: Evidence and Some Theory," Quarterly Journal of Economics, 115(1), 147-180.

Cochrane, J. H. (1999): "A Frictionless View of U.S. Inflation," in NBER Macroeconomics Annual 1998, ed. by B. S. Bernanke, and J. J. Rotemberg, pp. 323-384. MIT Press, Cambridge, MA.

- (2001a): "Long Term Debt and Optimal Policy in the Fiscal Theory of the Price Level," Econometrica, 69(January), 69-116.

- (2001b): "Money as Stock," Mimeo, University of Chicago.

Cogley, T., and T. J. Sargent (2002a): "Drifts and Volatilities: Monetary Policies and Outcomes in the Post WWII U.S.," Mimeo, Arizona State University.

- (2002b): "Evolving Post-World War II U.S. Inflation Dynamics," in NBER Macroeconomics Annual 2001, ed. by B. S. Bernanke, and J. J. Rotemberg. MIT Press, Cambridge.

Cohen, D., And C. Wyplosz (1989): "The European Monetary Union: An Agnostic Evaluation," in Macroeconomic Policies in an Interdependent World, ed. by R. C. Bryant, D. A. Currie, J. Frankel, P. Masson, and R. Portes, pp. 311-337. The Brookings Institution, Washington, D.C.

Coleman, II, W. J. (1991): "Equilibrium in a Production Economy with an Income Tax," Econometrica, 59(4), 1091-1104.

Cooley, T. F., S. F. LeRoy, and N. Raymon (1982): "Modeling Policy Interventions," Mimeo, University of California Santa Barbara.

- (1984): "Econometric Policy Evaluation: Note," American Economic Review, 74(3), 467-470.

Daniel, B. C. (2003): "Fiscal Policy, Price Surprises, and Inflation," Mimeo, SUNY Albany.

Davig, T. (2002): "Regime-Switching Debt and Taxation," Journal of Monetary Economics, forthcoming, Mimeo, The College of William and Mary.

- (2003): "Regime-Switching Fiscal Policy in General Equilibrium," Mimeo, The College of William and Mary.

Eichenbaum, M. (1992): "Comment on 'Interpreting the Macroeconomic Time Series Facts: The Effects of Monetary Policy'," European Economic Review, 36, 10011011. 
Favero, C. A., And T. Monacelli (2003): "Monetary-Fiscal Mix and Inflation Performance: Evidence from the US," CEPR Discussion Paper No. 3887.

Gallant, A. R., P. E. Rossi, and G. Tauchen (1993): "Nonlinear Dynamic Structures," Econometrica, 61(4), 871-907.

Gordon, D. B., And E. M. Leeper (1994): "The Dynamic Impacts of Monetary Policy: An Exercise in Tentative Identification," Journal of Political Economy, 102, 1228-1247.

Grilli, V. (1989): "Seigniorage in Europe," in A European Central Bank? Perspectives on Monetary Unificiation after Ten Years of the EMS, ed. by M. DeCecco, and A. Giovannini, pp. 53-79. Cambridge University Press, Cambridge.

Hanson, M. S. (2002): "The 'Price Puzzle' Reconsidered," Mimeo, Wesleyan University.

— (2003): "Varying Monetary Policy Regimes: A Vector Autoregressive Investigation," Mimeo, Wesleyan University.

Heller, W. W. (1967): New Dimensions of Political Economy. Norton, New York.

Janssen, N., C. Nolan, and R. Thomas (2001): "Money, Debt and Prices in the UK 1705-1996," forthcoming, Economica.

Kim, J., S. Kim, E. Schaumberg, and C. A. Sims (2003): "Calculating and Using Second Order Accurate Solutions of Discrete Time Dynamic Equilibrium Models," Mimeo, Princeton University.

King, M. (1995): "Commentary: Monetary Policy Implications of Greater Fiscal Discipline," in Budget Deficits and Debt: Issues and Options, pp. 171-183. Federal Reserve Bank of Kansas City, Jackson Hole Symposium.

King, R. G., And C. I. Plosser (1985): "Money, Deficits, and Inflation," vol. 22 of Carnegie-Rochester Conference Series on Public Policy, pp. 147-196. NorthHolland.

Leeper, E. M. (1991): "Equilibria Under 'Active' and 'Passive' Monetary and Fiscal Policies," Journal of Monetary Economics, 27(1), 129-147.

- (1993): "The Policy Tango: Toward a Holistic View of Monetary and Fiscal Effects," Federal Reserve Bank of Atlanta Economic Review, 78, 1-27.

Leeper, E. M., And J. E. Roush (2003): "Putting 'M' Back in Monetary Policy," Journal of Money, Credit, and Banking, forthcoming, NBER Working Paper No. 9552.

Leeper, E. M., C. A. Sims, and T. Zha (1996): "What Does Monetary Policy Do?," Brookings Papers on Economic Activity, 2, 1-63.

Leeper, E. M., And T. Zha (2003): "Modest Policy Interventions," Journal of Monetary Economics, 50(8), 1673-1700. 
Loyo, E. (1999): "Tight Money Paradox on the Loose: A Fiscalist Hyperinflation," Harvard University, mimeo.

Lubik, T. A., And F. Schorfheide (2003a): "Computing Sunspot Equilibria in Linear Rational Expectations Models," Journal of Economic Dynamics and Control, 28(2), 273-285.

- (2003b): "Testing for Indeterminacy: An Application to U.S. Monetary Policy," American Economic Review, forthcoming, Mimeo, Johns Hopkins University. LucAs, JR., R. E. (1976): "Econometric Policy Evaluation: A Critique," vol. 1 of Carnegie-Rochester Conference Series on Public Policy, pp. 104-130. NorthHolland.

Mackowiak, B. (2002): "Macroeconomic Regime Switching and Speculative Attacks," Mimeo, Humbolt University.

NiePelt, D. (2001): "The Fiscal Myth of the Price Level," Mimeo, IIES, Stockholm.

Obstfeld, M., and K. Rogoff (1983): "Speculative Hyperinflations in Maximizing Models: Can We Rule Them Out?," Journal of Political Economy, 91(August), $675-687$.

Ohanian, L. E. (1997): "The Macroeconomic Effects of War Finance in the United States: World War II and the Korean War," American Economic Review, 87(1), $23-40$.

Pechman, J. A. (1987): Federal Tax Policy. The Brookings Institution, Washington, D.C., fifth edn.

Poterba, J. M. (1994): "Federal Budget Policy in the 1980s," in American Economic Policy in the 1980s, ed. by M. Feldstein, pp. 235-270. University of Chicago Press, Chicago.

SAlA, L. (2003): "Testing the Fiscal Theory of the Price Level," Mimeo, Universita Bocconi.

Sargent, T. J. (1999): The Conquest of American Inflation. Princeton University Press, Princeton, NJ.

Sargent, T. J., and N. Wallace (1981): "Some Unpleasant Monetarist Arithmetic," Federal Reserve Bank of Minneapolis Quarterly Review, 5(Fall), 1-17.

Schmitt-Grohe, S., And M. Uribe (2004): "Solving Dynamic General Equilibrium Models Using a Second-Order Approximation to the Policy Function," Journal of Economic Dynamics and Control, 28(4), 755-775.

Schorfheide, F. (2003): "Learning and Monetary Policy Shifts," Mimeo, University of Pennsylvania.

Sidrauski, M. (1967): "Rational Choice and Patterns of Growth in a Monetary Economy," American Economic Review Papers and Proceedings, 57(2), 534-544. 
Sims, C. A. (1992): "Interpreting the Macroeconomic Time Series Facts: The Effects of Monetary Policy," European Economic Review, 36, 975-1000.

- (1994): "A Simple Model for Study of the Determination of the Price Level and the Interaction of Monetary and Fiscal Policy," Economic Theory, 4(3), 381399.

(1997): "Fiscal Foundations of Price Stability in Open Economies," Mimeo, Yale University.

Sims, C. A., And T. Zha (2002): "Macroeconomic Switching," Mimeo, Princeton University.

Stein, H. (1996): The Fiscal Revolution in America. AEI Press, Washington, D.C., second revised edn.

Steuerle, E. (2002): "Tax Policy from 1990 to 2001," in American Economic Policy in the 1990s, ed. by J. Frankel, and P. Orszag, pp. 139-169. MIT Press, Cambridge.

TAYlor, J. B. (1993): "Discretion versus Policy Rules in Practice," vol. 39 of Carnegie-Rochester Conference Series on Public Policy, pp. 195-214. North Holland.

- (1996): "Monetary Policy Implications of Greater Fiscal Discipline," in Budget Deficits and Debt: Issues and Options, pp. 151-170. Federal Reserve Bank of Kansas City, Jackson Hole Symposium.

- (1999a): "An Historical Analysis of Monetary Policy Rules," in Monetary Policy Rules, ed. by J. B. Taylor, pp. 319-341. University of Chicago Press, Chicago.

— (1999b): Monetary Policy Rules. University of Chicago Press, Chicago.

- (2000): "Reassessing Discretionary Fiscal Policy," Journal of Economic Perspectives, 14(3), 21-36.

Weil, P. (2003): "Reflections on the Fiscal Theory of the Price Level," Mimeo, ECARES.

Woodford, M. (1995): "Price-Level Determinacy Without Control of a Monetary Aggregate," vol. 43 of Carnegie-Rochester Conference Series on Public Policy, pp. 1-46. North-Holland.

— (1998): "Public Debt and the Price Level," Mimeo, Princeton University. (1999): "Comment on Cochrane's 'A Frictionless View of U.S. Inflation'," in NBER Macroeconomics Annual 1998, ed. by B. S. Bernanke, and J. J. Rotemberg, pp. 390-419. MIT Press, Cambridge, MA.

YAnG, S.-C. S. (2003): "Evidence of Tax Foresight," Mimeo, John Carroll University. 

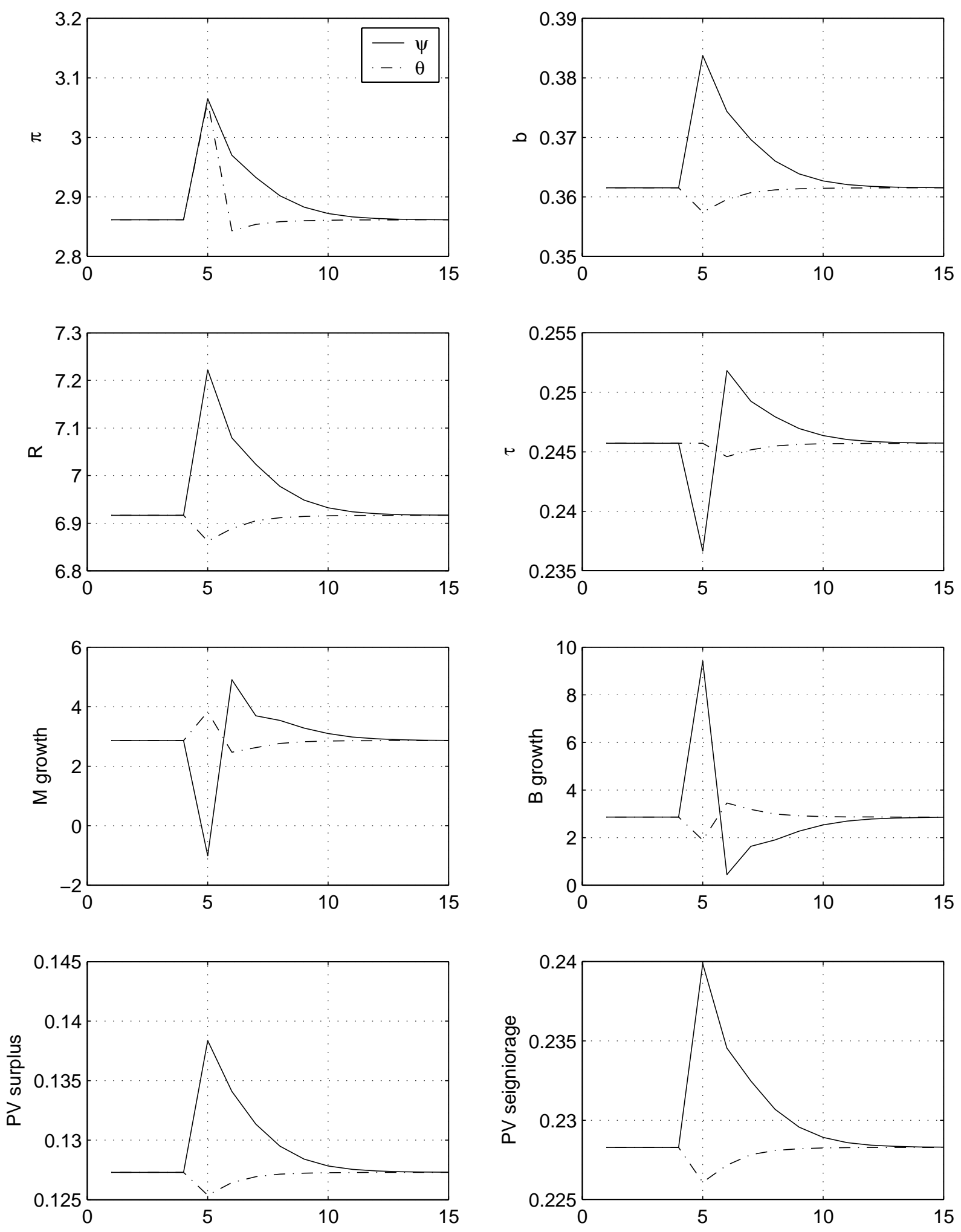

Figure 1. Impacts of Policy Shocks Conditional on Regime 1 (AM/FP) 

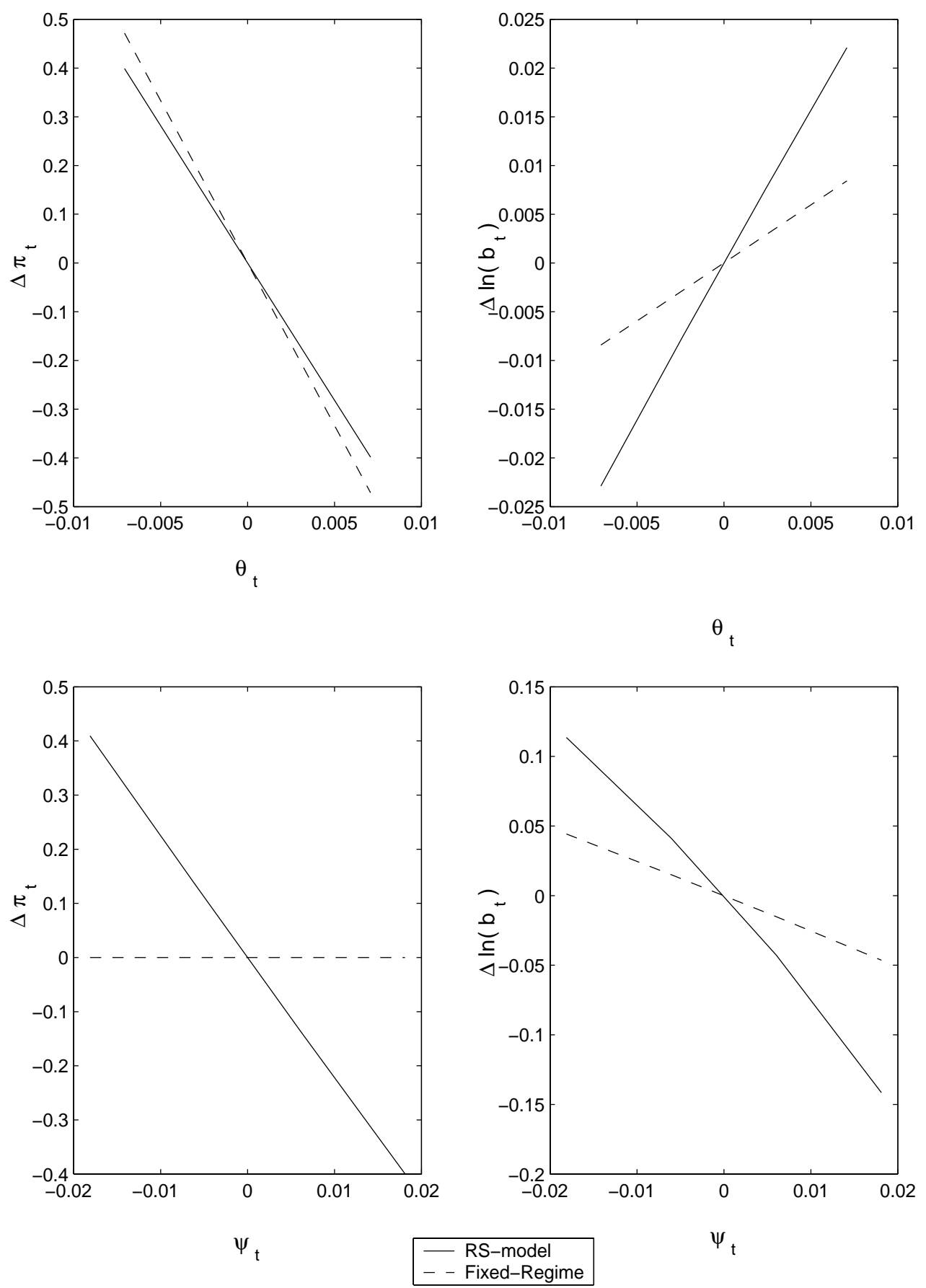

Figure 2. Regime 1 (AM/PF): Decision Rules in Switching- and Fixed-Regime Models 

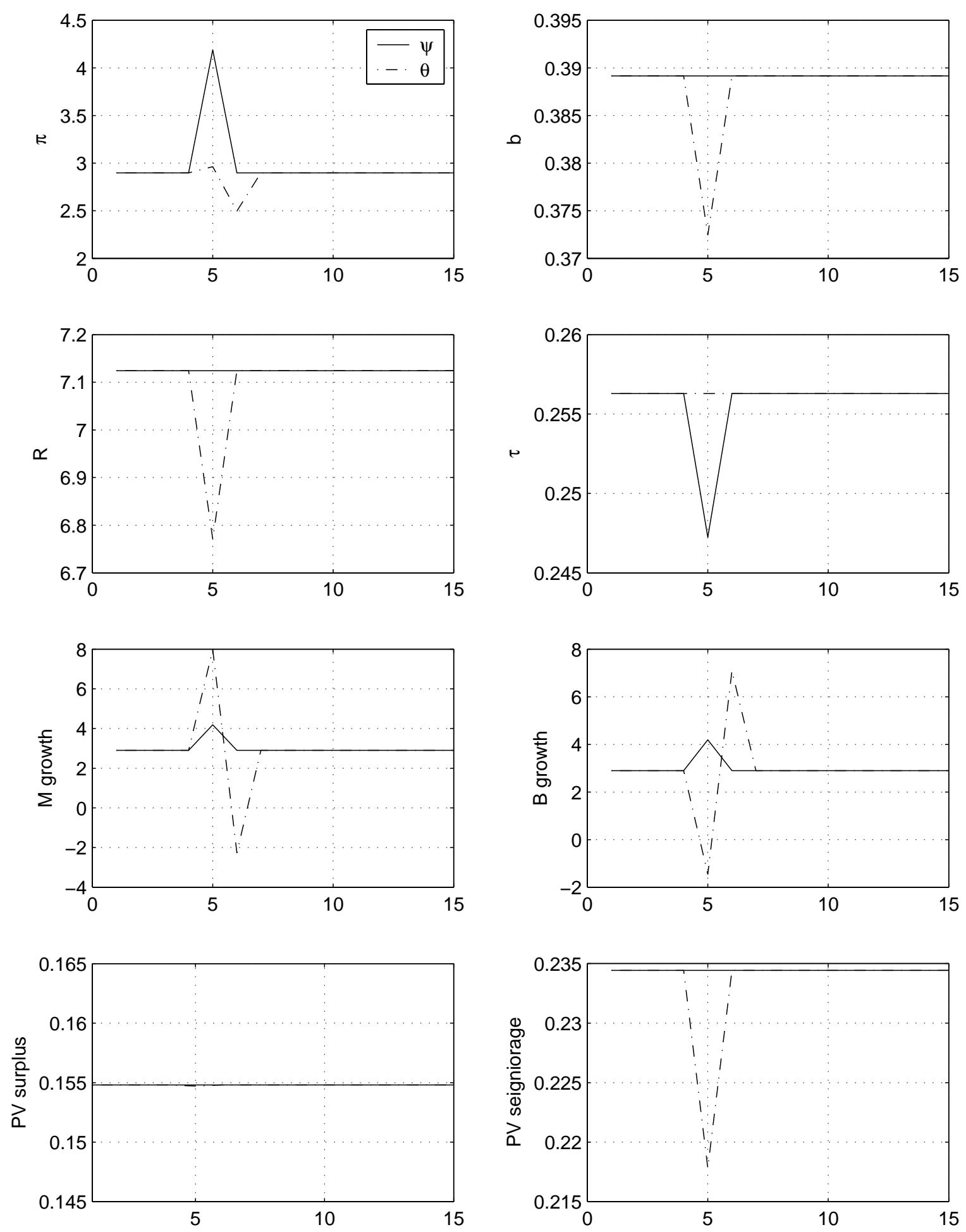

Figure 3. Impacts of Policy Shocks Conditional on Regime 2 (PM/AF) 


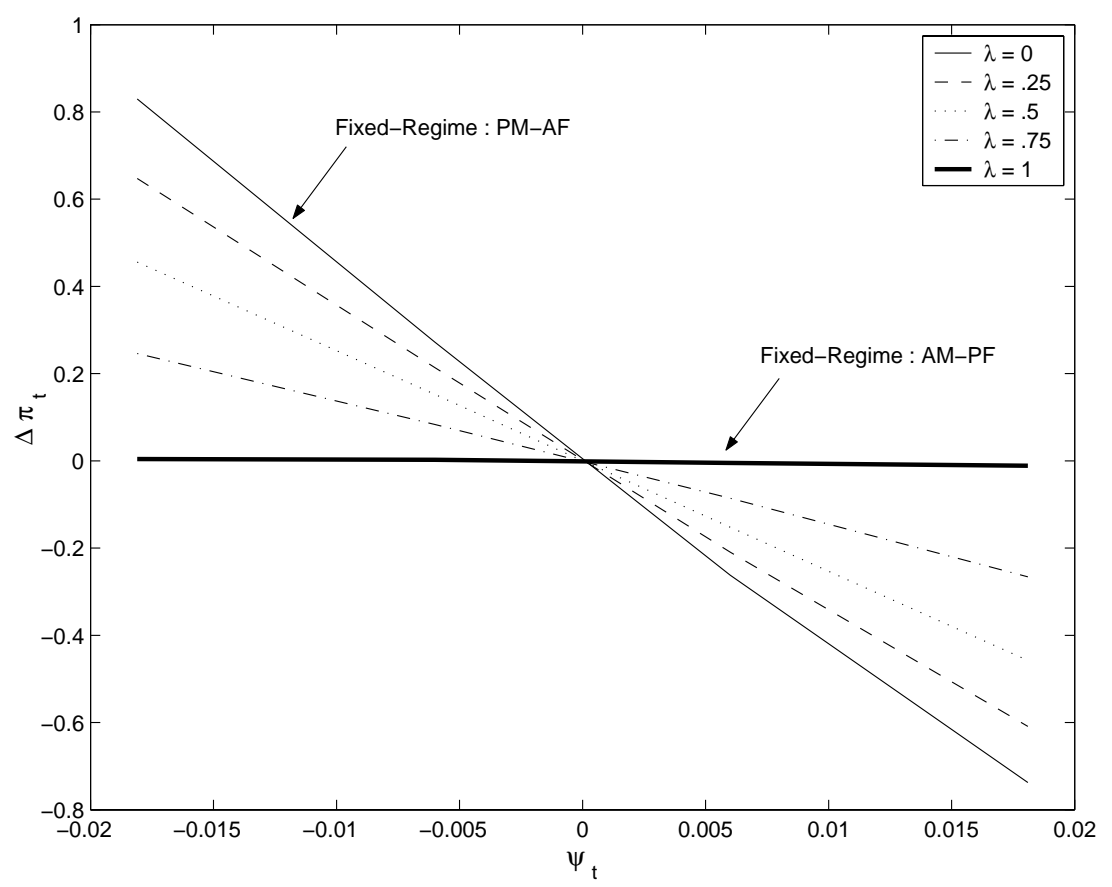

Figure 4. Regime 1 (AM/PF): Contemporaneous Impact of Taxes on Inflation as a Function of $\lambda$, Proportion of Time Spent in Regime 1. 


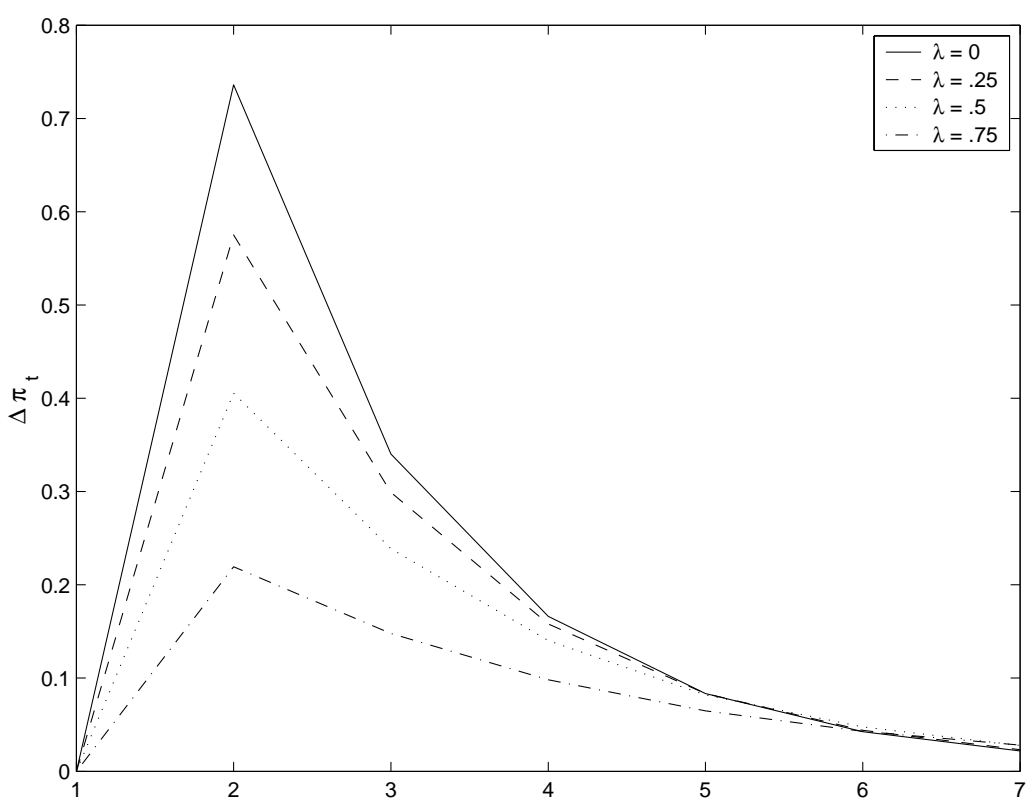

Figure 5. Regime 1 (AM/PF): Response of Inflation to Tax Cut in Period 2 as a Function of $\lambda$, Proportion of Time Spent in Regime 1.

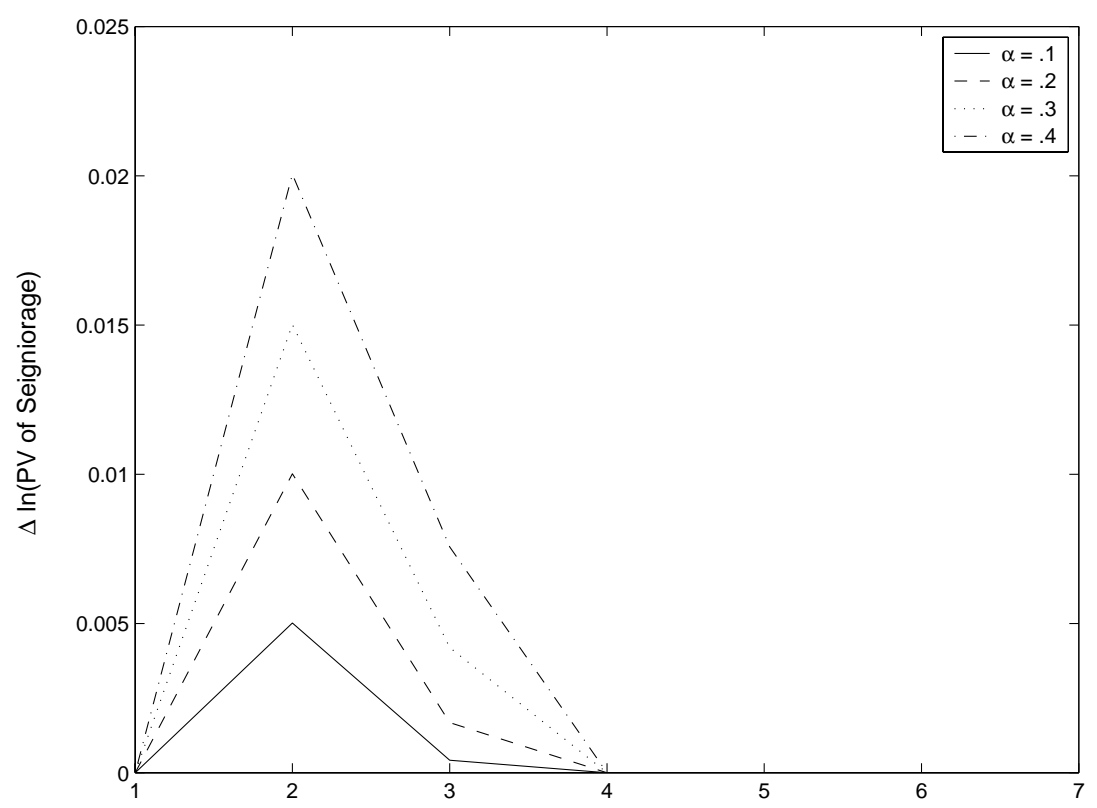

Figure 6. Fixed Regime (PM/AF): Response of Present Value of Seigniorage to Tax Cut in Period 2 as a Function of the Monetary Policy Response of the Interest Rate to Inflation 


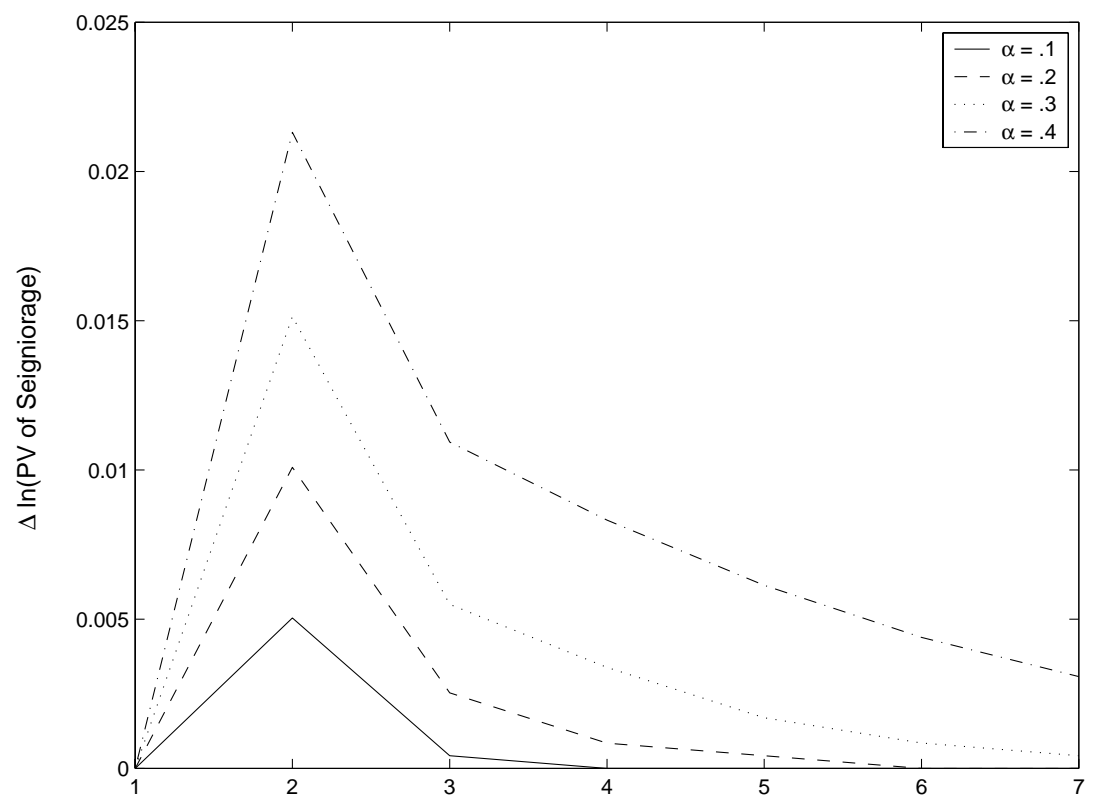

Figure 7. Regime 2 (PM/AF): Response of Present Value of Seigniorage to Tax Cut in Period 2 as a Function of the Monetary Policy Response of the Interest Rate to Inflation
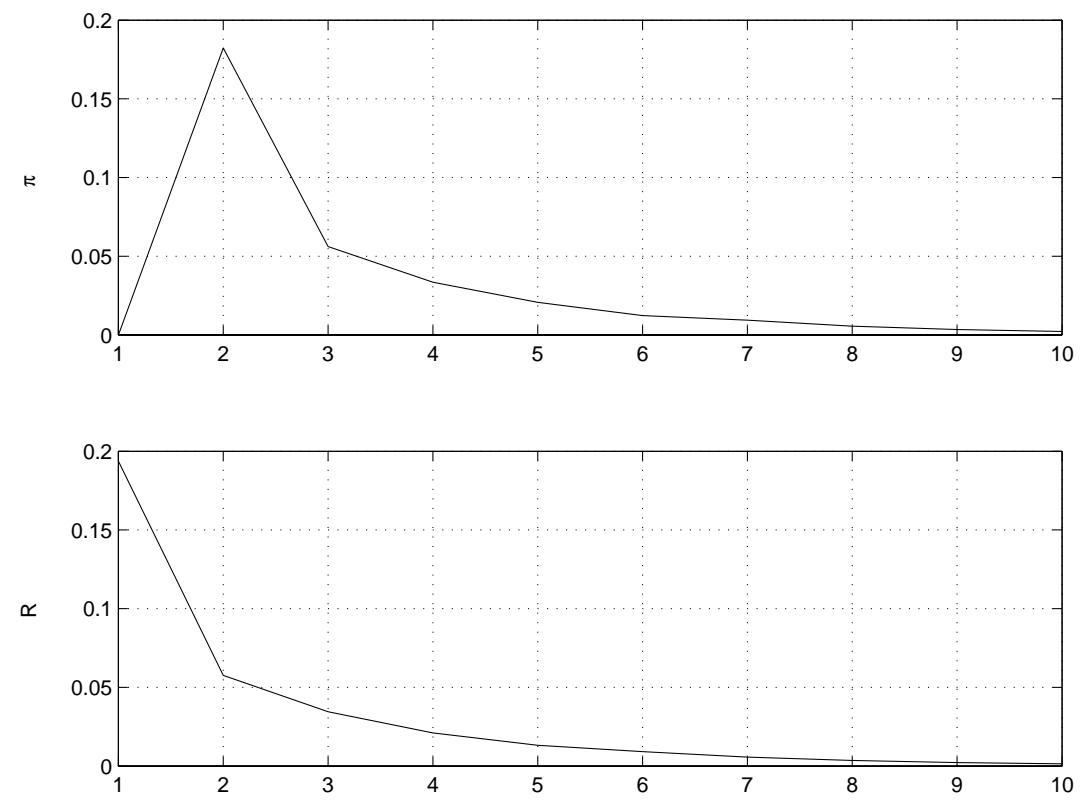

Figure 8. Responses to a Nominal Interest Rate Innovation: Using Data Simulated from Regime-Switching Model 

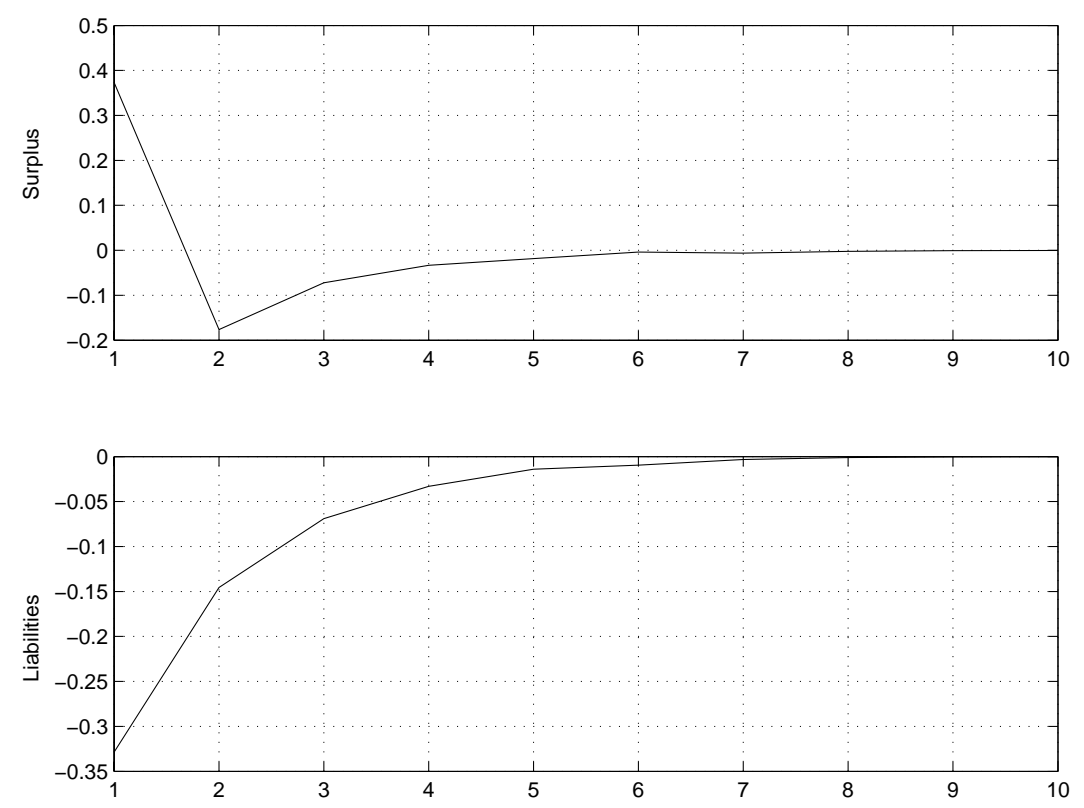

Figure 9. Responses to a Surplus Innovation: Using Data Simulated from Regime-Switching Model

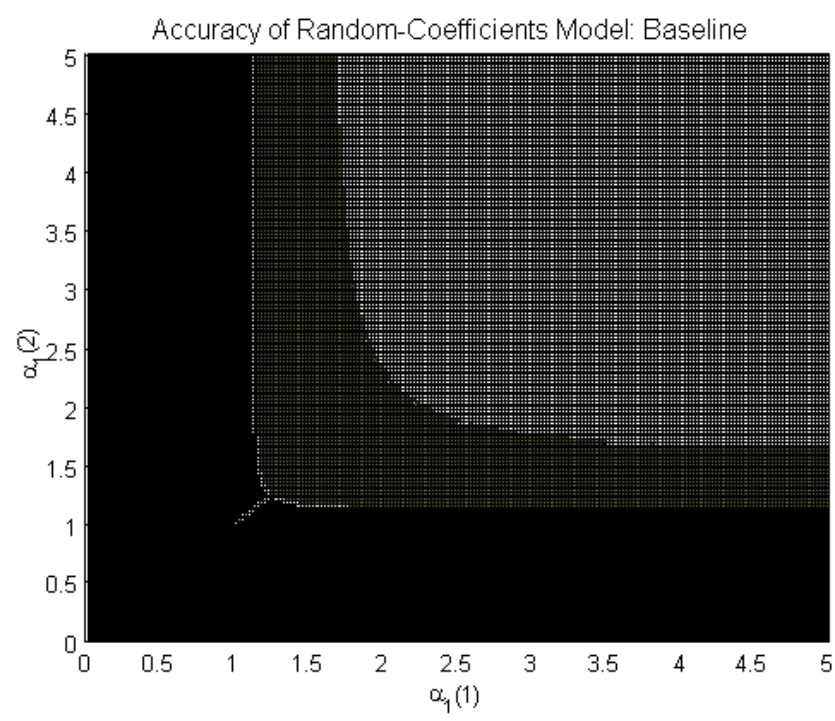

FIGURE 10. Light shading: linear methods and nonlinear model agree; middle shading: linear methods imply existence, nonlinear model implies nonexistence; dark shading: nonlinear model implies nonRicardian fiscal policy or indeterminacy. 


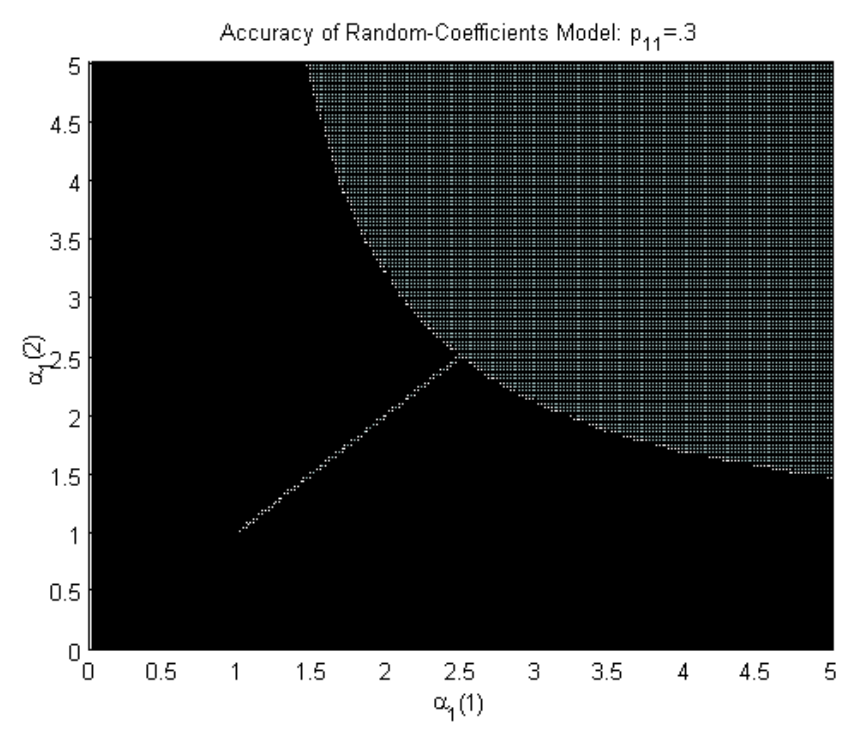

FIGURE 11. Light shading: linear methods and nonlinear model agree; middle shading: linear methods imply existence, nonlinear model implies nonexistence; dark shading: nonlinear model implies nonRicardian fiscal policy or indeterminacy.

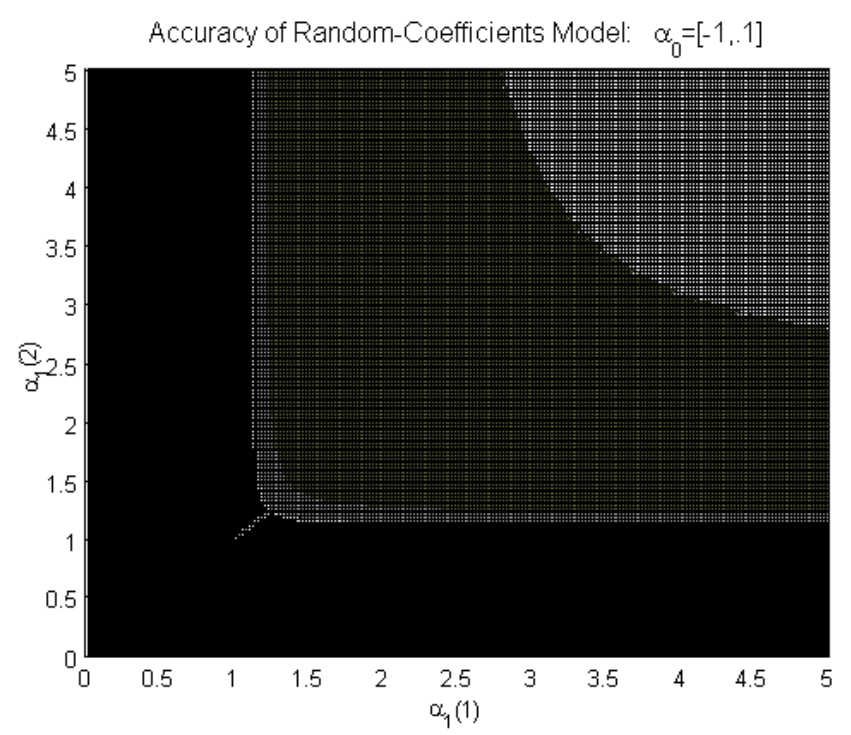

FIGURE 12. Light shading: linear methods and nonlinear model agree; middle shading: linear methods imply existence, nonlinear model implies nonexistence; dark shading: nonlinear model implies nonRicardian fiscal policy or indeterminacy. 